\title{
Exploration of the Face of the Turin Shroud. Pollens Studied by SEM Analysis
}

\author{
Gérard Lucotte \\ Institute of Molecular Anthropology, Paris, France \\ Email: lucotte@hotmail.com
}

Received 5 August 2015; accepted 27 September 2015; published 30 September 2015

Copyright (C) 2015 by author and Scientific Research Publishing Inc.

This work is licensed under the Creative Commons Attribution International License (CC BY). http://creativecommons.org/licenses/by/4.0/

c) (i) Open Access

\begin{abstract}
We studied by SEM-EDX analysis the pollens on the Face of the Turin Shroud. A total of ten pollen grains were found; they were photographed, characterised and analysed. Three of them (pollens p6, p7 and p10) belong to Ceratonia siliqua, the carob tree; one of them (pollen p1) belongs to Balanites aegyptiaca (the palm tree of the desert), and another one (pollen p9) belongs to Cercis siliquastrum (the Judean tree). These three plants have their geographical distributions in the Near-East; that is indicative of a Palestinian origin of the Turin Shroud. Two pollen grains ( $p 3$ and p4) belong to Myosotis ramosissima. Probably myositis flowers were deposited later on the Turin Shroud, as reverence for this venerable and symbolic object.
\end{abstract}

\section{Keywords}

Elemental Composition, Energy Dispersive X-Ray (EDX), EDX Spectrum, Face Area, Pollens and Spores, Scanning Electron Microscopy (SEM), Turin Shroud (TS)

\section{Introduction}

The Turin Shroud (TS) is a well-known object in which a body image is imprinted (Marion \& Lucotte, 2006). In 1973, the Swiss criminologist Max Frei took more than ten sticky-tape samples from the upper body image of the TS and identified 48 different varieties of pollen grains; in 1978 he took about twenty-six further samples. From these two different sources (and others), Frei identified 57 different plants on the TS, 56 of them being in the form of pollen. He claimed that the identification was confirmed both by optics and by Scanning Electron Microscope (SEM).

Frei wrote a short article (Frei, 1982) about his findings in an article published in 1982 in Shroud Spectrum International; but he died before he could produce a more detailed analysis on the subject, and the book he was writing "The pollens of the Shroud of Turin" was never published (Farey, 2014). 
In his article, Frei classified the 57 different plants he found on TS as belonging to few very characteristic groups: Group 1, desert plants (16 species), either from sand deserts or haplotypes, i.e. plants growing in soils with a very high concentration of salt; Group 2, plants of rocky hills and stony places in Palestine and neighbouring countries (7 species); Group 3, Mediterranean plants (16 species); Group 4, plants from Anatolia, mostly steppic plants (16 species); Group 5, plants growing near Constantinople (some plants mentioned in Groups 2, 3 and 4, which could be found on both sides of the Bosphorus); Group 6, plants widely distributed in Central Europe, or cosmopolitans (12 species). As Groups 1, 2 and 3 plants on TS from Palestine and Anatolia were so numerous - compared to the species from Europe-Frei considered that a casual contamination from, or a pollen transport from, the Near East by storms in different seasons could not be responsible for their presence, and that the pollen-deposits were a valuable confirmation that the TS travelled from Palestine through Anatolia to Constantinople, Italy and France.

Frei was accused of fraud, mainly because the SEM photos of pollen grains he reported in his article (those of Roemeria hybrida, Epimedium pubigerum, Haplophyllum tuberculatum and Cistus creticus) were in fact reference prepared pollens, and not the pollen grains coming from the TS. Other criticisms about Frei's sticky-tape were: he had found too many grains, only about half of them were from wind-pollinated plants, the geographical and biological distributions were unconvincing, and he had been impossibly precise about identification (for a full-length discussion of the subject at this date, see Maloney (1990)).

In 1999, Danin et al. (1999) reported their results of TS pollen determination in the 1973 tapes and in fourteen of the twenty-seven sticky-tapes sampled by Frei in 1978. The most frequent type of pollen of all 313 grains studied is that of Gundelia tournefortii, which accounts for $29.1 \%$ of the grains investigated and identified (these are $44.6 \%$ of all pollen grains with positive identification). Also relatively common were pollen types recognized as Cistaceae (7.3\%) and Apiaceae (4.2\%), and less for Poaceae and Papillonaceae (and for Quercus). There is a large amount of unidentified grains (34.8\% of total counted pollens). Pollen grains of the large family Chenopodiaceae can only be determined to subfamilial groupings. Although Prosopis farcta, Ricinus communis and Scabiosa prolifera were the only species found by Frei to confirm, most of the species he found (of Acacia, Anabasis, Artemisia, Atraphaxis, Capparis, Carduus, Cedrus, Corylus, Echinops, Fagonia, Haplophyllum, Hyoscyamus, Linum, Paliurus, Reaumuria and Tamarix) were confirmed at the genus level only.

Out of respect for both Frei's expertise and for the fact that he had spent the last nine years of his life working for the TS, his findings had been treated as corresponding to a pioneer approach in the field and as a way into many other publications (Danin's book as an example) (Danin, 2010) as the incontrovertible proof that the Shroud must have been from Jerusalem. Note that although Frei had done his doctorate thesis in palynology, he was not a professional palynologist.

We have recently (Lucotte, 2010) studied the TS pollens by SEM. TS samples concerned various debris of linen threads and fibers, obtained by aspiration at the occasion of the 1988 dating. On the basis of such criteria as size, form and appearance, we have found a total number of 88 pollen grains; but 54 of them $(61.5 \%)$ are not identifiable, because of altered structures or intense mineral deposits at the surface. Among the eighteen convinced pollens, four of them belong to some species of Chenopodiaceae, and three belong to some species of Leguminoseae. Two recent pollen grains belong to the Salix genus and seven belong to Corylus avellana, two of which are now mainly European species (probably their origins are due to contamination of the aspirator used to clean the TS, just prior to sampling for the 1988 dating).

We present here a detailed SEM study of TS pollens (and spores) located in a sticky-tape sampled in the region of the Face (Lucotte, 2012).

\section{Materials and Methods}

The material (Lucotte, 2012) is a small (1.36 mm height, $614 \mu \mathrm{m}$ wide) sticky-tape triangle (Figure 1) at the surface of which portions of fibers (Lucotte, in press), pollen grains and spores (this study), and some plaques of organic matter were deposited. As declared by Riggi di Numana (Lucotte, 2012), this sticky-tape triangle is one part of a larger piece he placed directly (during the 1978 official sampling) on the TS surface, near one "blood area" of the Face.

More than 2500 particles, greater than $1 \mu \mathrm{m}=1 \mu$, can be observed at the surface of the triangle; all of them were studied by optical microscopy, SEM and EDX analysis. For practical reasons, the surface of the triangle was subdivided into 19 sub-samples areas (areas A to S) containing almost all the particles observed. The positions of each particle sticking on the triangle surface were located in a double system of coordinates (in 186 
squares of $50 \times 50 \mu \mathrm{m}=2500 \mu \mathrm{m}^{2}$ of the total surface).

Particles of the samples were observed, without any preparation, on the adherent part of the surface of the triangle. The observations were conducted by SEM, using a Philips XL30 instrument (environmental version); GSE and BSE procedures are used, the last one to detect heavy elements. Elemental analyses for each particle were realised by X-ray microfluorescence (XRMF), this SEM microscope being equipped with a Bruker AXS energy dispersive X-ray (EDX); the system of analysis is PGT (Spirit Model, of Princeton Gamma Technology).

Because the two first described pollens of Ceratonia siliqua are isolated from other particles deposited on the surface of the triangle, we completed SEM studies concerning them by optical observations (using a photomicroscope Zeiss, model III 1972, and its petrographic version).

We have realised our palynological observations (in optic microscopy) of reference pollens in the Palynological Unit at the "Muséum d'Histoire Naturelle de Paris". We had there also access to the Rossignol palynothèque (Rossignol, 1969), specially devoted to Near East pollens. Palestinian pollen grains produced by trees and tree-like shrubs are described by Horowitz \& Baum (1967). For SEM studies concerning pollens, we have followed the reference book of Hesse et al. (2009).

\section{Results}

A total number of ten pollen grains (pollens) are found on the triangle. Figure 1 shows the locations of each of them in the different areas of the surface of the triangle; these pollens are designated as indicated in Table 1.

\section{Pollens P1-1 (b54) and P1-2 (b55)}

Pollens p1 and p2 (Figure 2) are two adjacent pollen grains. Pollen $\mathrm{p} 1$ is seen in polar view, and $\mathrm{p} 2$ in equatorial view; but they are not pollens of the same species of this dyad.

All these characteristics (diameter excepted) permit us (according to Horowitz \& Baum (1967)) to diagnose the 1 pollen as belonging to the species Balanites aegyptiaca (family Zygophyllaceae). The corresponding tree (in vernacular terms) is "the palm tree of the desert".

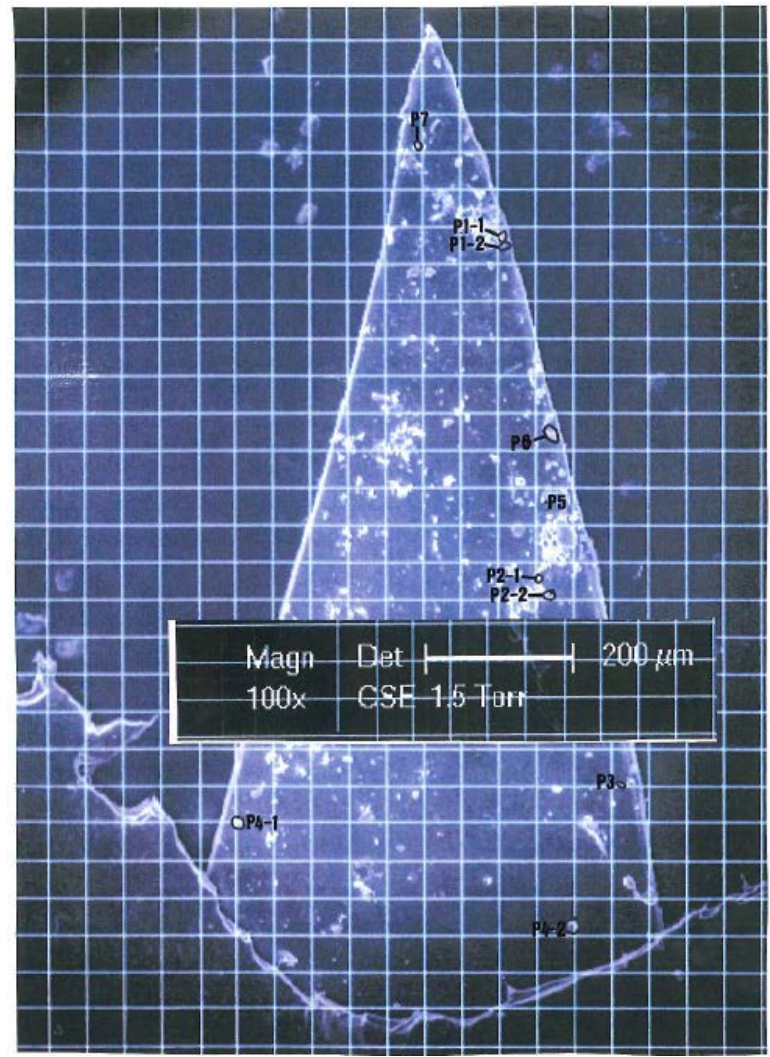

Figure 1. Locations of the ten pollens on the surface of the triangle (magnification factor: $100 \times$ ). 

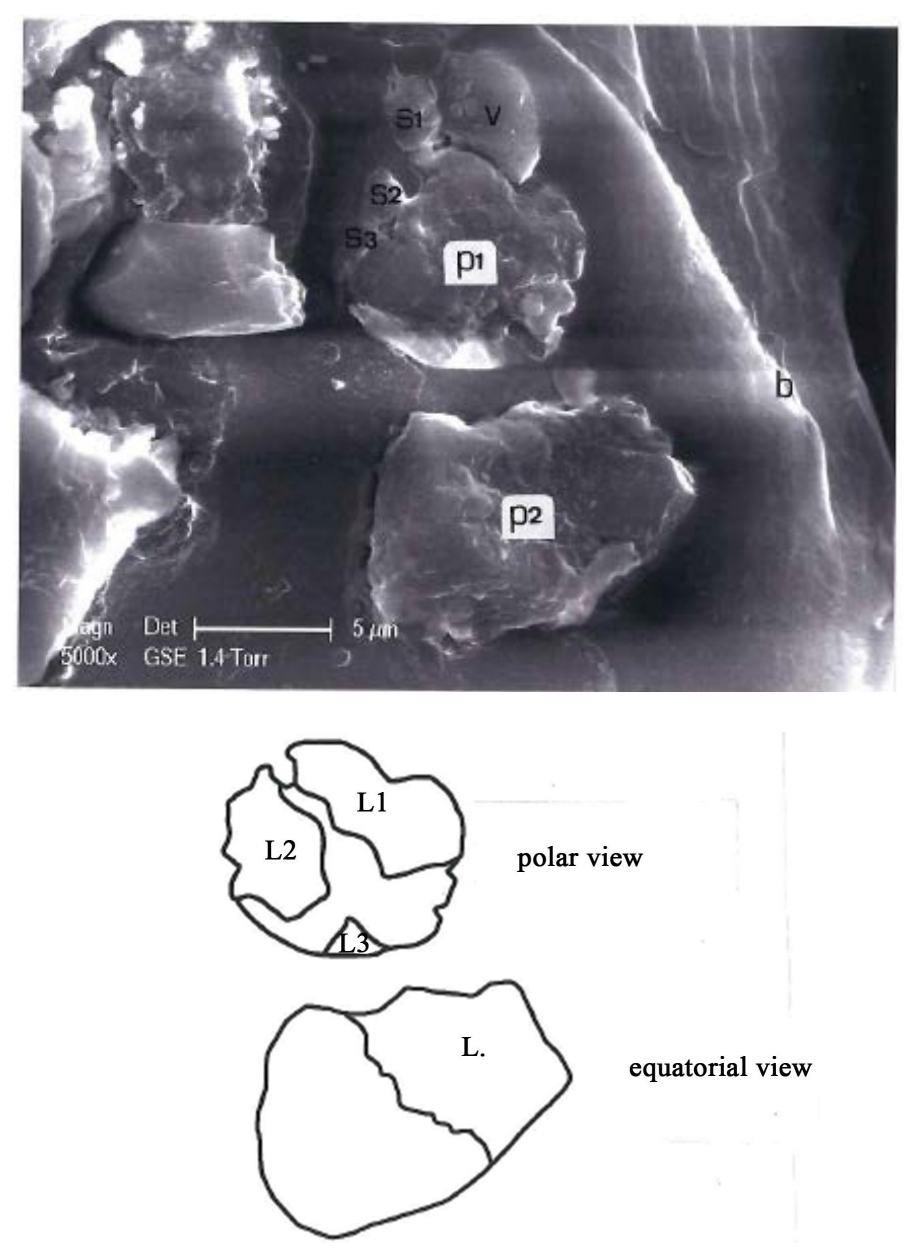

Figure 2. Above: SEM photography $(5000 \times)$ of pollens $p 1$ and $\mathrm{p} 2 ; \mathrm{b}$, border of the triangle; $v, s 1, \mathrm{~s} 2$ and $\mathrm{s} 3$ are B particles adjacent to p1. Below: schematic representation of the two pollen grains. For p1, L1, L2 and L3 are the three lobes; for $\mathrm{p} 2, \mathrm{~L}$. is the flattened zone of this pollen grain.

Table 1. Nomenclatures and locations of the ten pollen grains studied here.

\begin{tabular}{|c|c|c|c|}
\hline Pollen numbers & Designations & Particle numbers & Locations in areas of the triangle \\
\hline p1 & $\mathrm{P} 1-1$ & b54 & B \\
\hline p2 & $\mathrm{P} 1-2$ & b55 & B \\
\hline p3 & $\mathrm{P} 2-1$ & h1 & $\mathrm{H}$ \\
\hline p4 & $\mathrm{P} 2-2$ & h12 & $\mathrm{H}$ \\
\hline p5 & P3 & q7 & Q \\
\hline p6 & P4-1 & $\mathrm{m} 14$ & M \\
\hline p7 & $\mathrm{P} 4-2$ & $\mathrm{r} 9$ & $\mathrm{R}$ \\
\hline p8 & P5 & f34 & $\mathrm{F}$ \\
\hline p9 & P6 & $\mathrm{d} 24-25$ & $\mathrm{D}$ \\
\hline p10 & P7 & a33 & A \\
\hline
\end{tabular}


The photography of Figure 3 shows the p1 pollen. It is a circular pollen (diameter: about $10 \mu$ ). This tricolporate grain has three big pores (circular or elliptic); colpi is straight, narrow, lined by short thickening interrupted around the pores.

Such a difference in size (from about $25 \mu$ for the reference pollen, to $10 \mu$ for p1) can be easily explained: 1 is a dry pollen, with a reduction in size of about one half.

Elementary analysis of $\mathrm{p} 1$ (Figure 3, spectrums) shows that it is constituted mainly of organic matter (carbon and oxygen). But an important component of $\mathrm{p} 1$ consists of an alumino-silicate mineral material, iron-rich; there is also salt $(\mathrm{ClNa})$.

Bright subparticles analyses deposited on p1 show the composition of this mineral: some form of clay, iron-rich (frequently manganese is together with iron in natural deposits); iron oxide confers a red colour to this sort of clay.

That clay with salt is common components of the red soils in arid and desert zones of the planet.

Figure 4 shows pollen $\mathrm{p} 2$, seen in equatorial view. It is a pollen grain, because of its prolate form (longest axis about $25 \mu$ ) and that it shows some ornamentation of its surface (for its left part). Elementary analysis reveals that it is mainly constituted of organic matter, with a very low level of calcification.

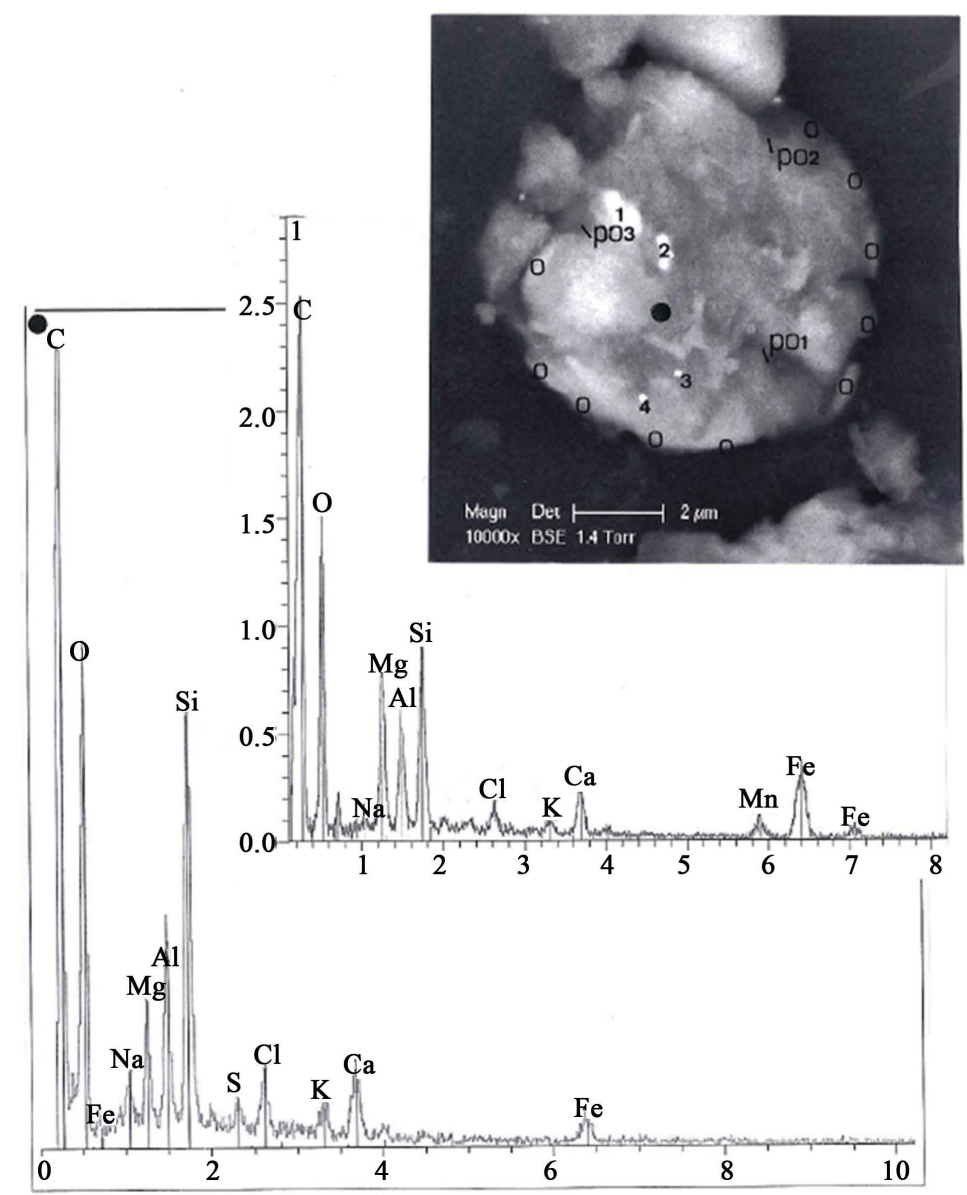

Figure 3. Above: SEM photography (10,000×, in BSE) of pollen p1; p01, 2 and 3: the three pores; O: shows the straight colpi parts. Subparticles 1, 2, 3 and 4 are bright in BSE. It is at the black point indicated that the elementary analysis of $\mathrm{p} 1$ is realised. Below: two spectrums. The lower spectrum corresponds to elementary analysis of $\mathrm{p} 1$ at the black point indicated. The upper spectrum corresponds to elementary analysis of subparticle 1 (subparticles 2, 3 and 4 have similar spectrums). C, carbon; O, oxygen; $\mathrm{Na}$, sodium; $\mathrm{Mg}$, magnesium; Al, aluminium; $\mathrm{Si}$, silicium; $\mathrm{S}$, sulphur; $\mathrm{Cl}$, chlorine; $\mathrm{K}$, potassium; $\mathrm{Ca}$, calcium, $\mathrm{Mn}$, manganese; $\mathrm{Fe}$, iron. In spectrums the horizontal axis is graduated in kilo-electron volts $(\mathrm{keV})$, and heights of the peaks are proportional to quantities of elements in the samples. 


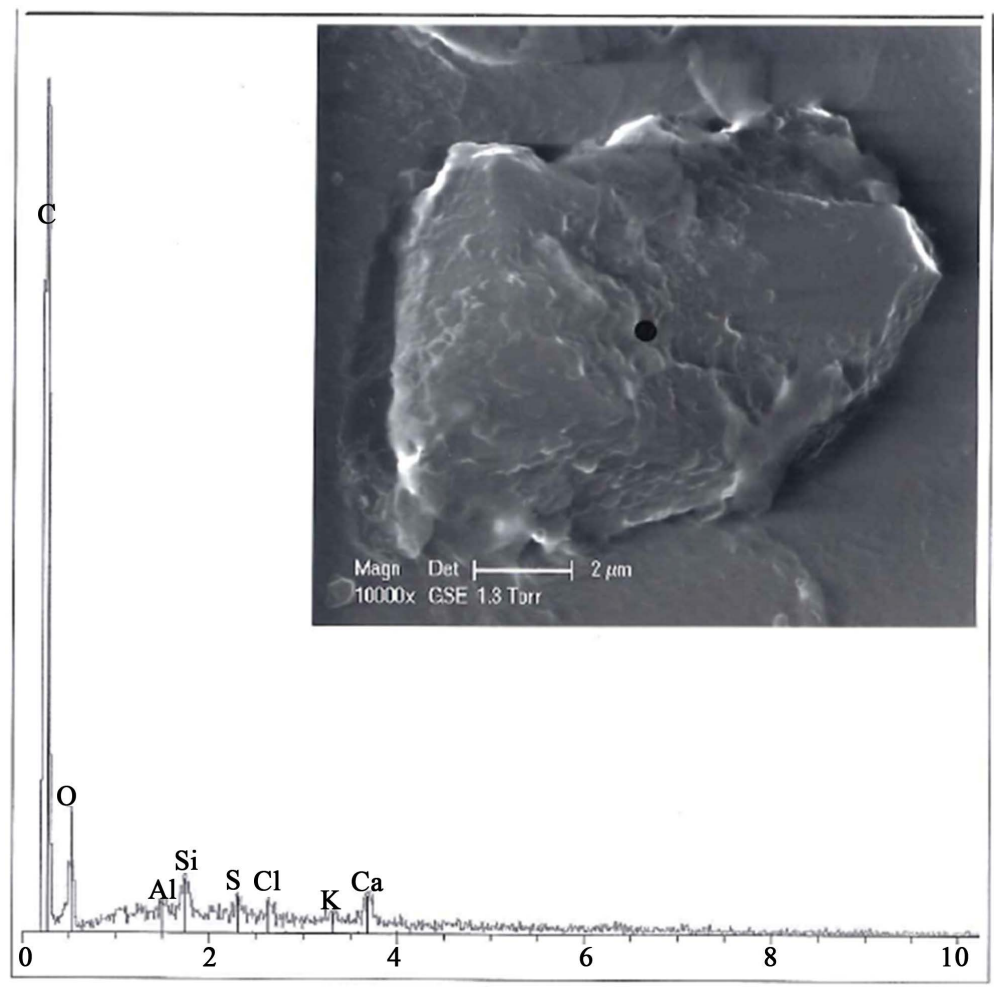

Figure 4. Above: SEM photography $(10,000 \times$, in BSE) of p2. The black point indicates the place of the elementary analysis. Below: spectrum of $\mathrm{p} 2$ at this place.

\section{Pollens P2-1 (h1) and P2-2 (h12)}

Pollens p3 and p4 (Figure 5) are two neighbour pollen grains located in the area $\mathrm{H}$ of the triangle. Both are rectangular pollens. They belong to the same plant species, and so constitute a real dyad.

Figure 6 shows an enlarged view of p3. Its structure is notably altered, but we can distinguish its rectangular form (maximal length of about $8-10 \mu$ ), with at least one prominent longitudinal crest at its surface. Elementary analysis shows that this pollen is completely calcified.

The rectangular form of pollen p4 (also highly calcified) is more apparent in Figure 7. Its maximal length is about $15 \mu$, for about $10 \mu$ high. Three longitudinal prominent crests are visible on its surface.

In the medium part of this pollen grain, into spaces between longitudinal crests, we can distinguish a characteristic pattern of its ornamentation: a diamond-shaped (losange), with a central relief inside. Figure 8 shows these peculiar features in an enlarged view.

This singular pattern of ornamentation is highly characteristic of the rectangular pollen of Myosotis ramosissima (Hesse et al., 2009). It is remarkable that the calcification process had permitted such a conservation (in form, size and ornamentation) of pollens $\mathrm{p} 3$ and $\mathrm{p} 4$.

We have studied reference pollens from Myosotis arvensis, M. sylvatica, M. alpestris, $M$. decumbens and $M$. palustris: they are prolates, isopolars and heterocolpates. They differ notably in size (but always in the little size range); generally they present a narrowing equatorial zone. None of them have the characteristics in size, form and ornamentation that Myosotis ramosissima have.

Pollen P3 (q7)

Figure 9 shows pollen $\mathrm{p} 5$. It is a crushed pollen (length $=7 \mu$ ) where three colpis, starting from an unjagged apex, are discernable. Elementary analysis of this apex shows that the pollen is mainly composed by organic matter (but the corresponding spectrum indicates a very important calcium component).

The structure of this pollen is better seen on the photography of Figure 10 (SEM photography taken in BSE), because colpis (richer in calcium) appear as white compared to grooves (richer in organic matters) that they separate. High resolution photography of Figure 11 shows distinctly the differential pattern between constitutive calcite micrograins (in relief) of colpi 1, compared to those (in hollows) of groove s2. 


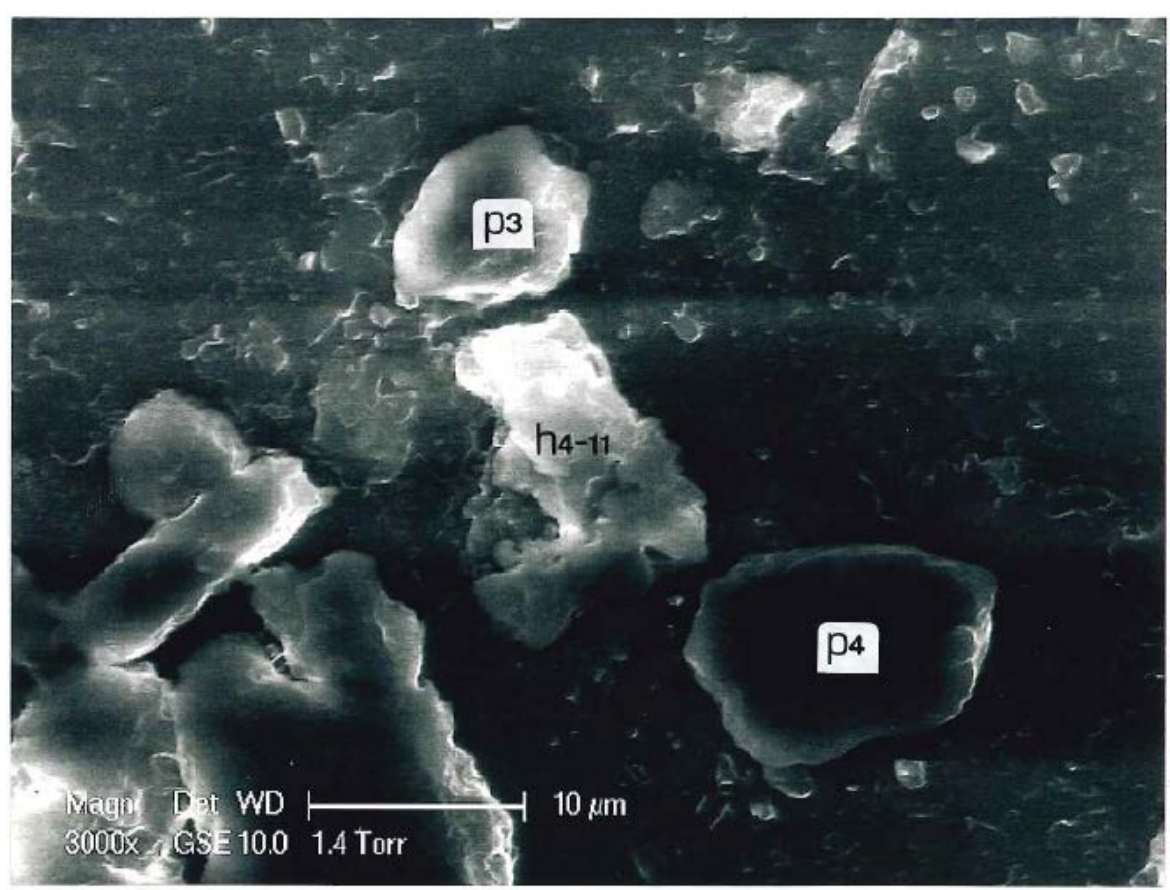

Figure 5. SEM photography $(3000 \times)$ of pollen $\mathrm{p} 3$ and $\mathrm{p} 4$. They are separated by the particle h4-11.

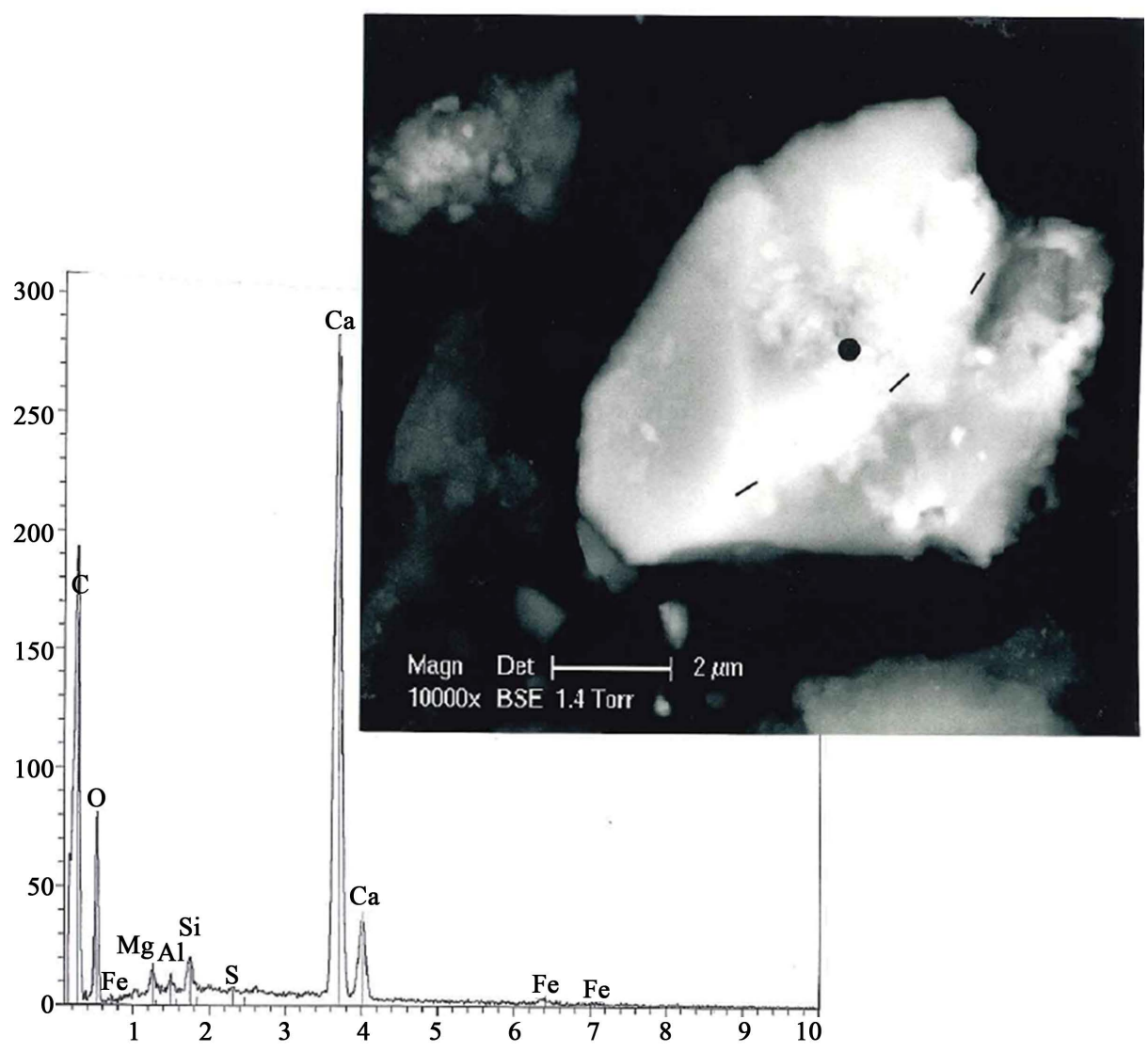

Figure 6. Above: SEM photography $(10,000 \times$, in BSE) of pollen p3. Short lines indicate the direction of the main longitudinal crest. Below: elementary analysis of $\mathrm{p} 3$ at the black point. 

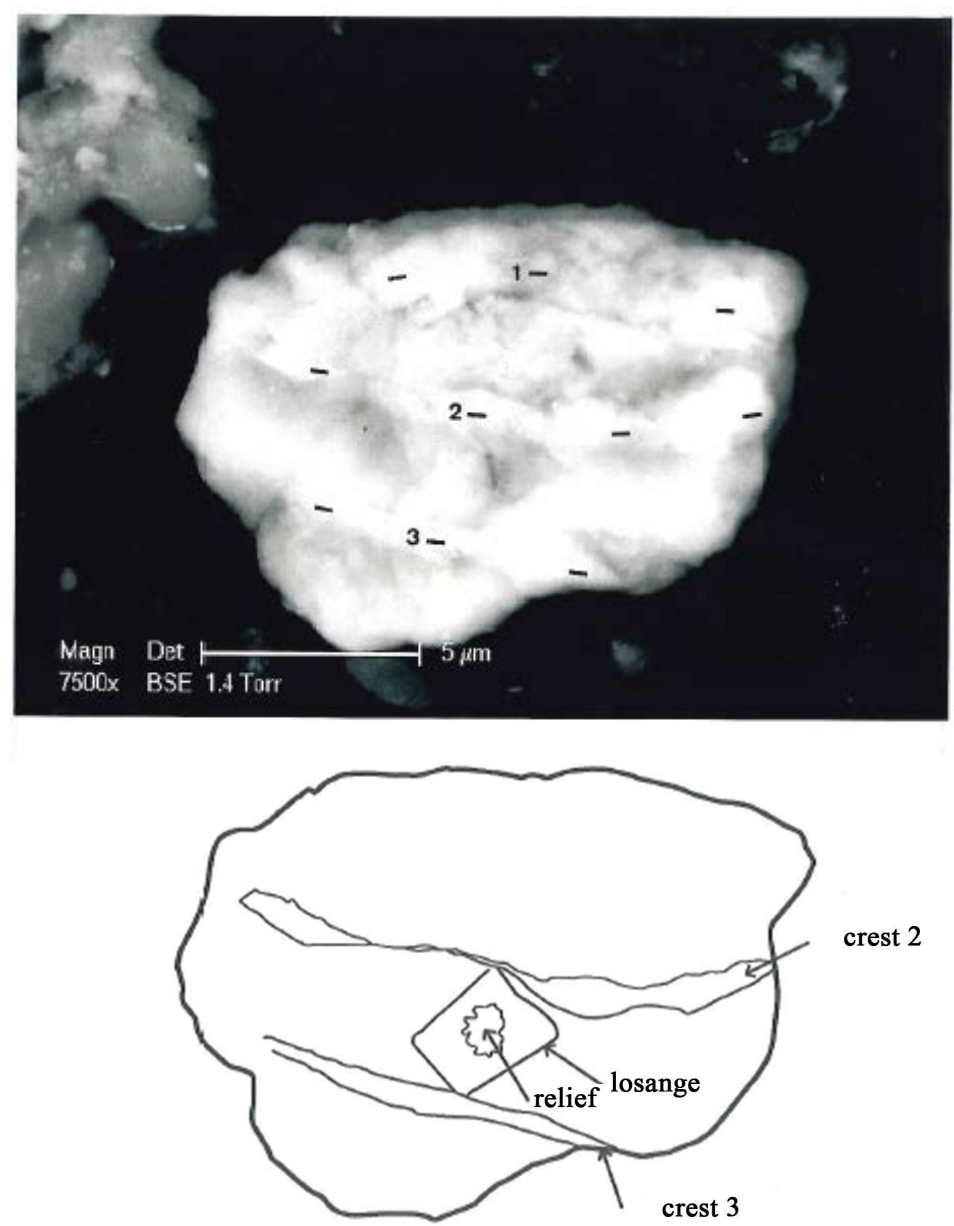

Figure 7. Above: SEM photography (7500×, in BSE) of pollen 4 . Short lines indicate crests 1,2 and 3. Below: schematic representation of pollen.

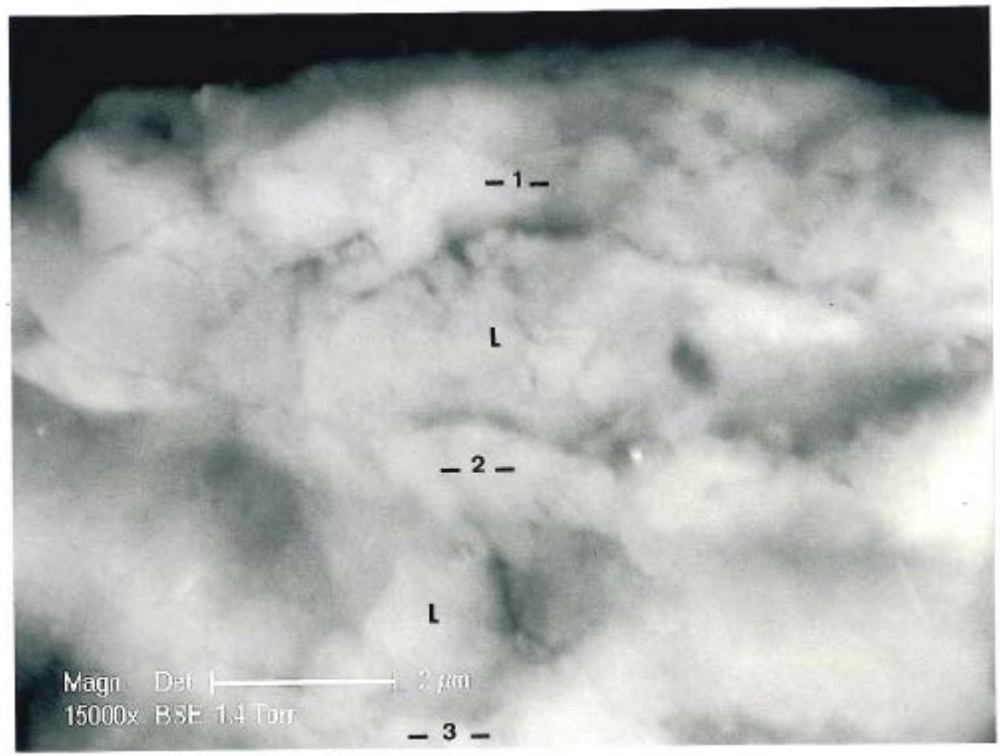

Figure 8. SEM photography $(15,000 \times$, in BSE) showing an enlarged view of the pollen $\mathrm{p} 4$ highest part. L: losanges; 1, 2 and 3: longitudinal crests. 


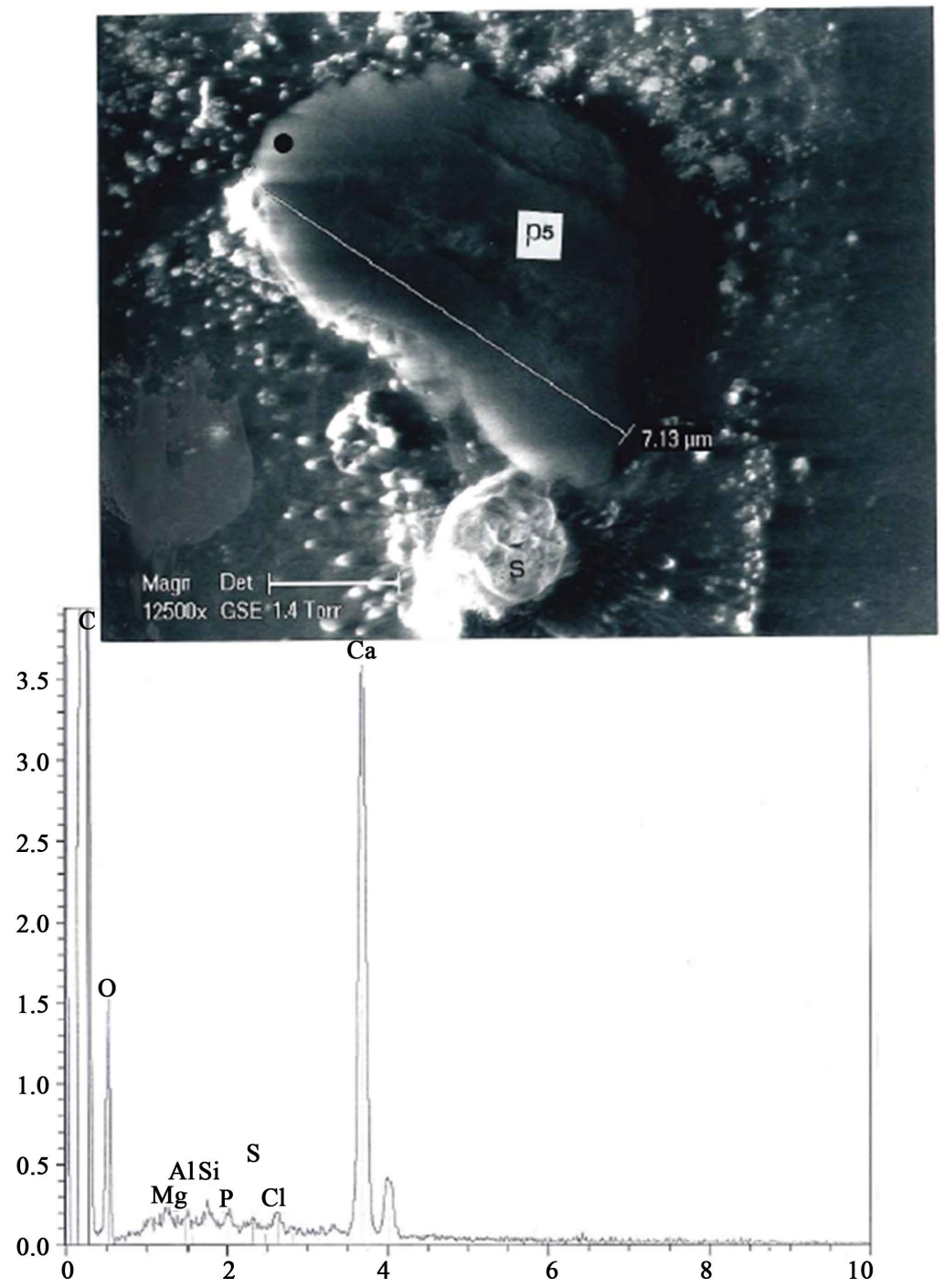

Figure 9. Above: SEM photography $(12,500 \times)$ of p5; s: a spore, adjacent to p5. Below: spectrum at the black point indicated in the apex.

The image of such a crushed pollen is very similar to the dry pollens of Galium rotundifolium reported by Hesse et al. (2009). That not implies that this pollen p5 belongs to these species (the most-commonly found species of this genus in Europe), but it belongs certainly to the Galium genus. Water loss of one half or more can explain the little dimensions of $\mathrm{p} 5$, compared to its normal counterpart.

Pollen P4-1 (m14) and P4-2 (r9)

Pollen p6 (Figure 12) is a circular-elliptic pollen, which dimensions are $11.4 \times 10.7 \mu$. At least three lobes are visible, and (perhaps?) some pores at the periphery. This pollen—by form, size and general aspect—is greatly similar to pollen 7 .

Elementary analysis of pollen p6 (Figure 13) shows that it is essentially constituted of organic matter; but there is on the spectrum an important peak of calcium. Some calcium carbonate sub-particles cover the pollen.

In optical microscopy (Figure 14) pollen p6 appears as a round pollen of yellow-brown colour; the pollen border is darker. Contrary to neighbouring particles of calcium carbonate, this pollen grain does not show any birefringency when illuminated in polarized light.

Pollen p7 (Figure 15) is a rounded pollen. Its maximal dimensions are about $17 \times 24 \mu$, but these measurements are biased because upper lobes (and mainly the upper-right one) are partially deployed. At last two of these lobes are visible, and three pores. 


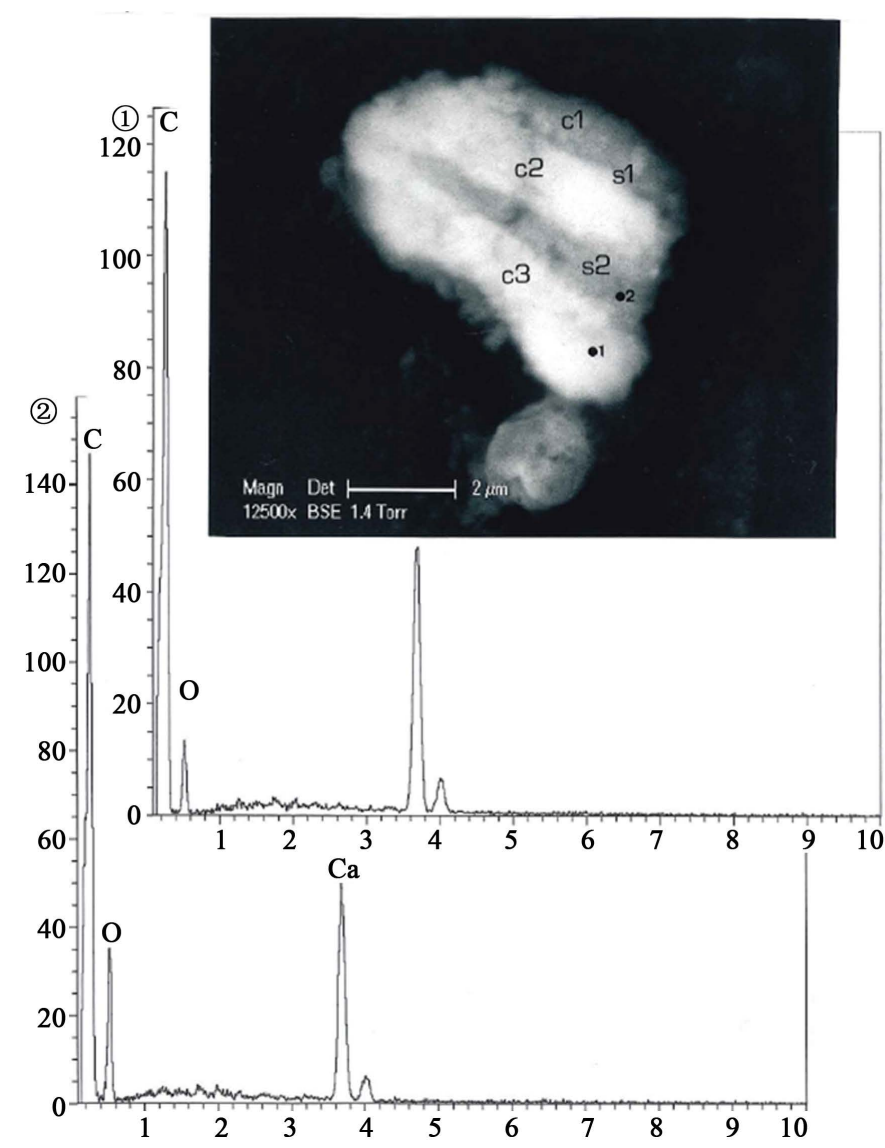

Figure 10. Above: SEM photography $(12,500 \times$, in BSE) of p5; C1, C2 and C3, the three apparent colpis; s1 and s2, the two grooves separating colpis. Below: spectrum 1 (taken at the black point 1 indicated, in $\mathrm{C} 3$ ); spectrum 2 (taken at the black point 2 indicated, in s2).

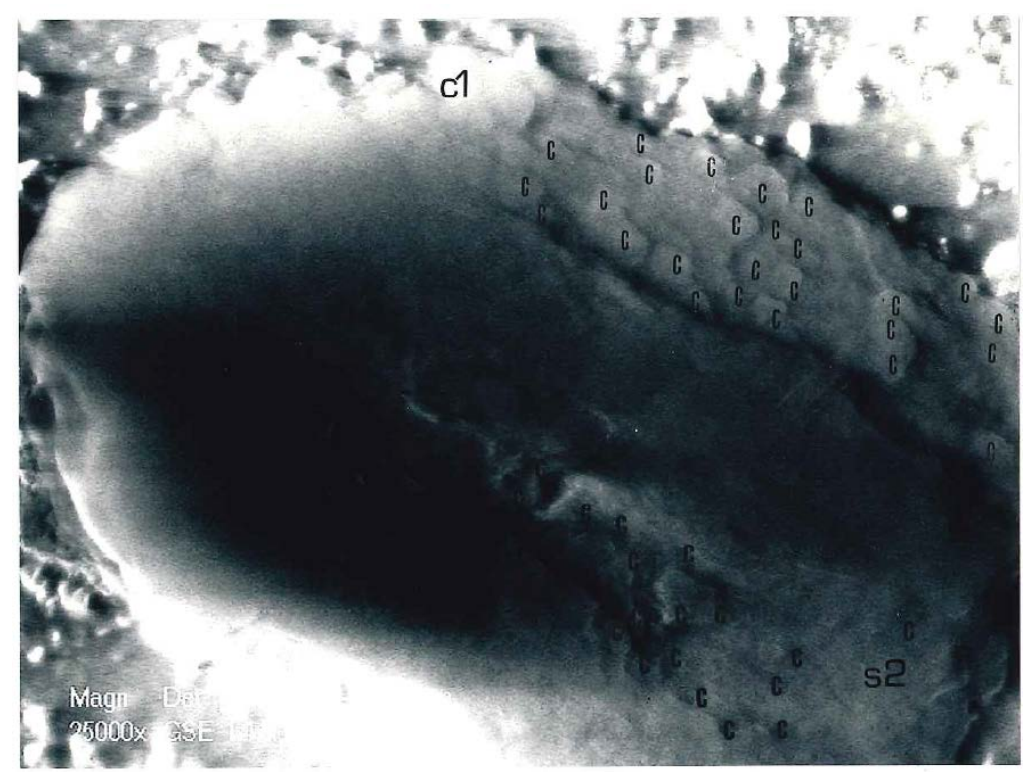

Figure 11. SEM photography $(25,000 \times)$ of the $5^{\prime}$ apex. C (in thin letters) indicate micrograins of calcite constituting the $\mathrm{c} 1 \mathrm{colpi}$; $\mathrm{C}$ (in thick letters) indicate micrograins of calcite constituting the s2 hollow. 

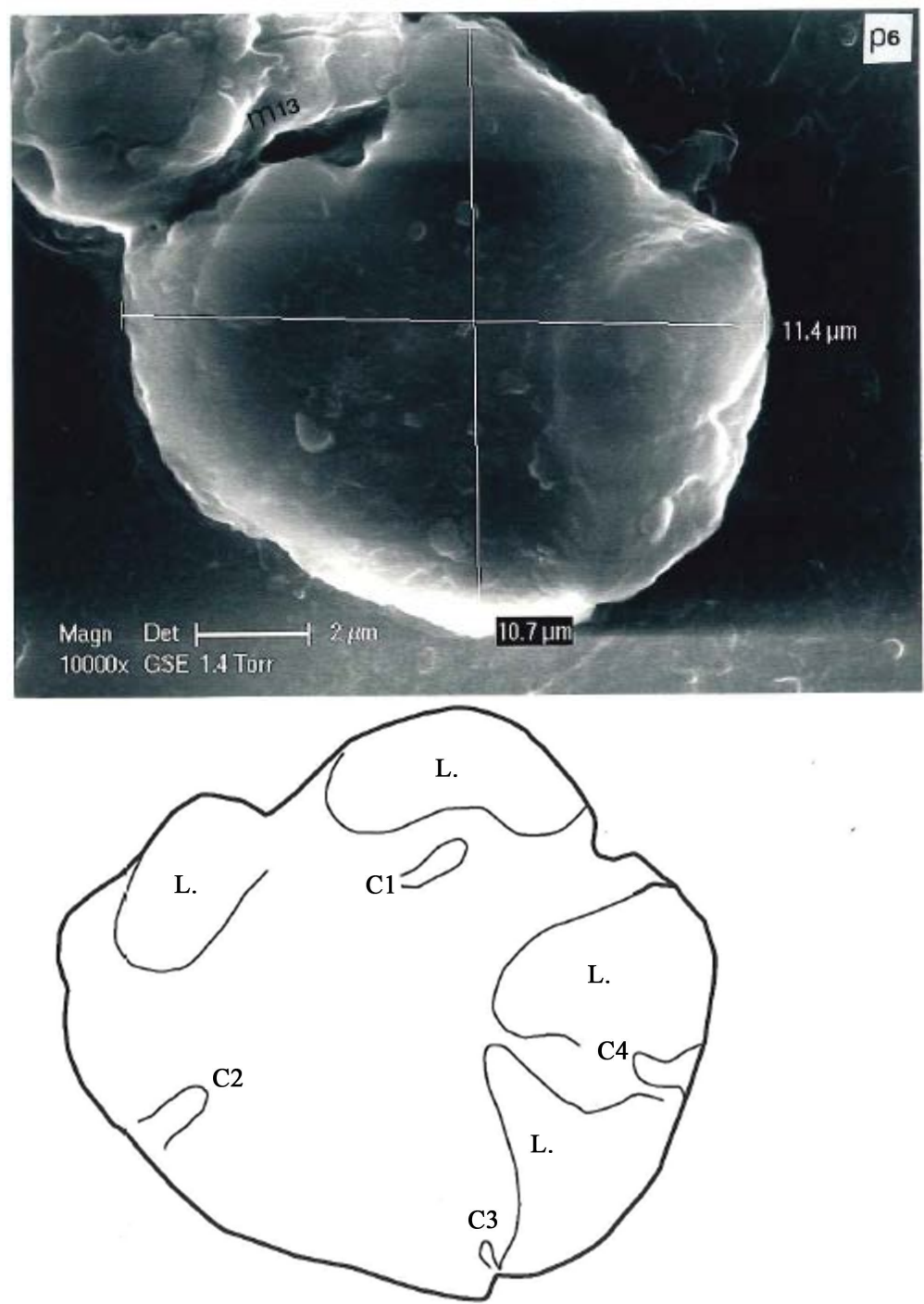

Figure 12. Above: SEM photography $(10,000 \times)$ of pollen $\mathrm{p} 6$; $\mathrm{m} 13$ is a calcium carbonate particle in the $\mathrm{M}$ area adjacent to $\mathrm{p} 6$. Below: schematic representation of this pollen grain. $\mathrm{L}$ : lobes, or parts of lobe; $\mathrm{C} 1, \mathrm{C} 2, \mathrm{C} 3$ and $\mathrm{C} 4$, possible emplacements of pores.

By aspect, this pollen (diameter excepted) is compatible with the Ceratonia siliqua species diagnosis (according to Horowitz \& Baum (1967)): polar view circular to sub-square; tetracolporate or rarely tricolporate grain; colpis narrow, straight; pores slightly elongated equatorially. The difference in size (from about $25 \mu$ for the reference pollen, to $17 \mu$ for $\mathrm{p} 7$ ) can be explained because $\mathrm{p} 7$ is a dry pollen.

Elementary analysis of $\mathrm{p} 7$ (Figure 16, spectrums) of the upper-right lobe shows a spectrum rich in organic matter, with relatively higher proportions of sulphur and calcium among the little peaks. The spectrum taken in the middle part of the pollen grain shows-among the mineral elements-relatively higher proportions of sulphur and calcium, but also of silicium and chlorine. The silicium peak (together with magnesium, aluminium, potassium and iron) corresponds to the clay-mineral alumino-silicate iron-rich already described for pollen 1 , and the chlorine peak (together with sodium) corresponds to salt.

Elementary analysis of sub-particle number 3 (white in BSE) shows a spectrum relatively rich in sulphur and calcium, which corresponds to gypsum (a calcium sulphate). Gypsum, as salt and the red alumino-silicate, is also a common mineral component of arid and desertic soils.

Figure 17 shows a high-resolution SEM photography of a portion of the tectum surface of the p7 pollen, located at some place in the upper-right lobe; this in order to study the perforate tectum aspect of Ceratonia sili- 


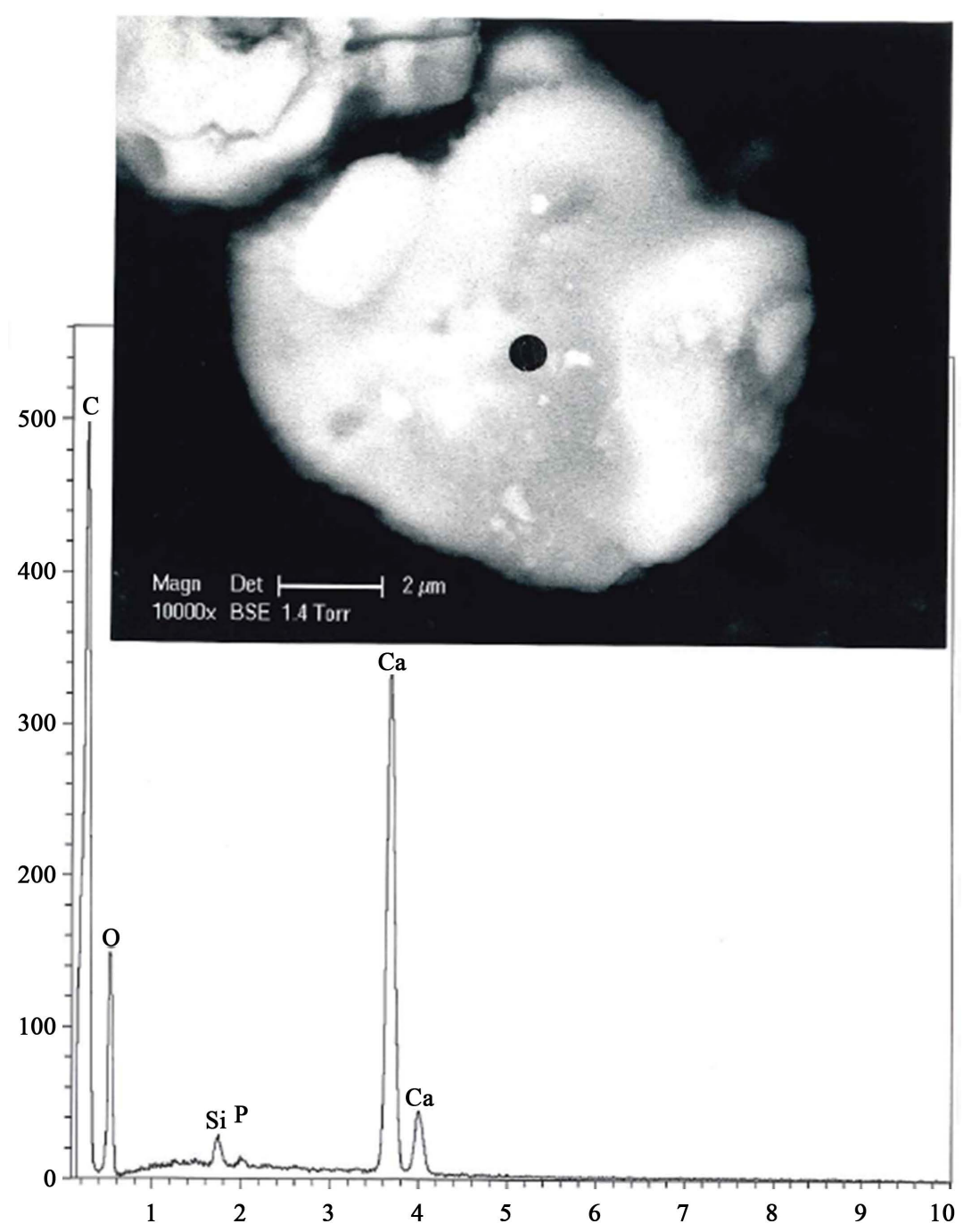

Figure 13. Above: SEM photography $(10,000 \times$, in BSE) of pollen p6. The black point indicates the place, in the center of the pollen, where elementary analyses were realised. Below: spectrum at the black point.
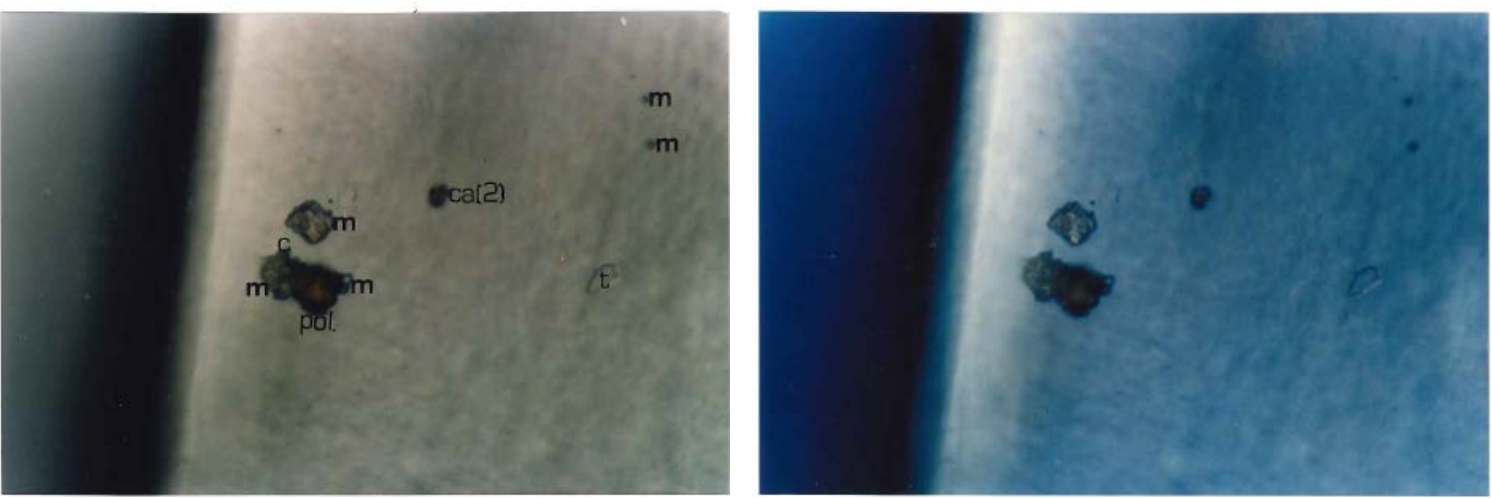

Figure 14. Study of pollen p6 in optical microscopy. Left: part of the M region of the triangle surrounding p6 (normal light, $\mathrm{x} \approx 1000$ ). The pollen $\mathrm{p} 6$ is designated as pol. Particles designated as $\mathrm{m}$ are masks (particles deposited at the surface, on the other side of the sticky-tape of the triangle); the three $\mathrm{m}$ particles surrounding pol. are calcium carbonate particles; $\mathrm{c}$ is the calcium carbonate particle $\mathrm{m} 13$; ca are two joined particles of calcite ( $\mathrm{m} 7$ and $\mathrm{m} 7$ '); $\mathrm{t}$ is a hole in the sticky-tape. Right: the same view, in polarized light. 

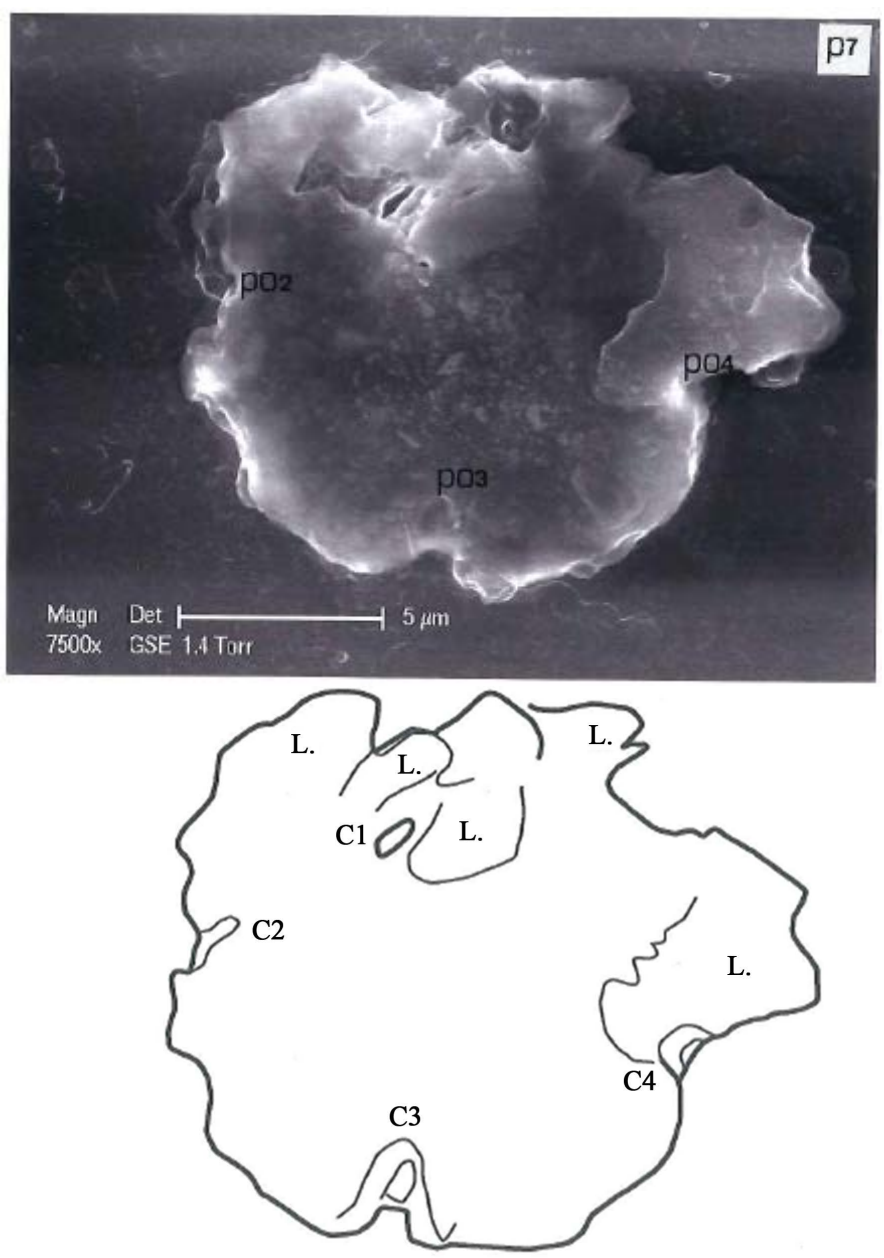

Figure 15. Above: SEM photography $(7500 \times)$ of pollen $\mathrm{p} 7$. The three pores po2, 3 and 4 are intricated. Below: schematic representation of this pollen grain. L. (lobes); C2, C3 and C4 (pores).

qua signalled in Horowitz \& Baum (1967) and well described in SEM by Ferguson (1980). But, if we have some evidence of the perforate nature of this tectum, the photography shows that perforations are plug up by fine dusts, and that the surface of the tectum is all covered by mineral sub-particles of various sizes (an usual aspect for unprepared pollens).

In optical microscopy (Figure 18) pollen p7 appears as a round pollen of yellow-brown colour. The pollen border is slightly darker; the upper-right lobe is completely dark.

\section{Pollen P5 (f34)}

Pollen p8 is a small spherical pollen grain (Figure 19, photography) that, because of its rounded appearance and its small size (diameter of about $3 \mu$ ) looks like a spore. It has a cup-shaped form (so it is a dry pollen). Its surface shows papules (external protuberant reliefs that cover internal columellas) and pores. Pores (not so numerous) are visible on the photography at the interior of the cup; they have one or several granules in the centre.

For some characterisation, $\mathrm{p} 8$ pollen is a very little spherical periporate grain. It is tectate, with columellas. Pores, relatively large in diameter, have granules in the centre. This description corresponds to the pollens belonging to species of the Chenopodiacaea family. But it is very difficult to distinguish the pollen grains of plants of this family; because of the small size, it is not a pollen of some species belonging to the Chenopodium, Haloxylon or Suaeda genders.

Elementary analysis of this pollen in its centre (Figure 19, spectrum) shows that it is mainly constituted of organic matter. Among the small peaks in the spectrum, silicium is preponderant, and the second peak in importance is that of calcium; there is evidence of salt. 


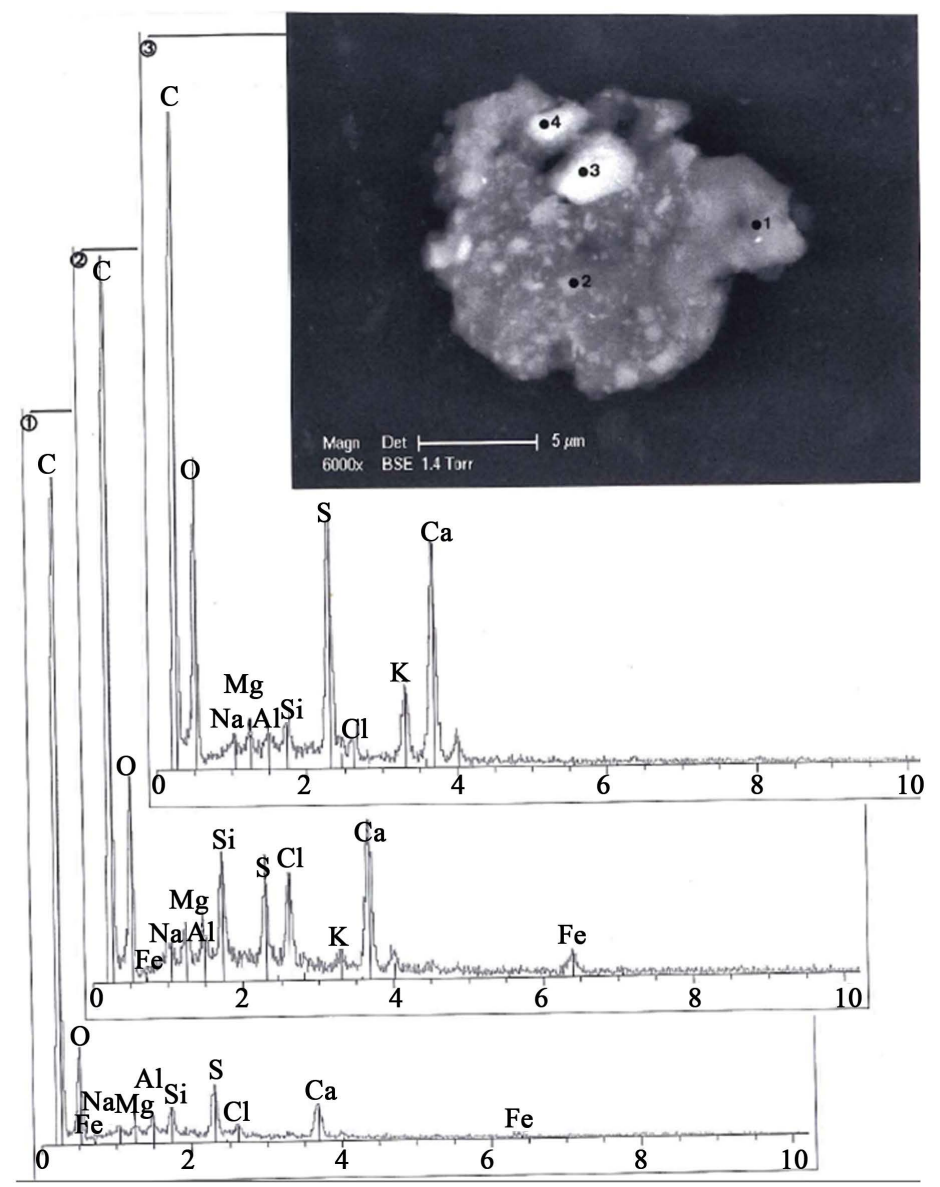

Figure 16. Above: SEM photography $(6000 \times$, in BSE) of pollen p7. Black points 1, 2, 3 and 4 indicate the different parts of the pollen where elementary analyses were realised. Below: the spectrums. Spectrum 1 corresponds to elementary analysis at point 1 ; spectrum 2 to the analysis at point 2, and spectrum 3 to the analysis at point 3 (spectrum at point 4 is identical to that found at point 3 ).

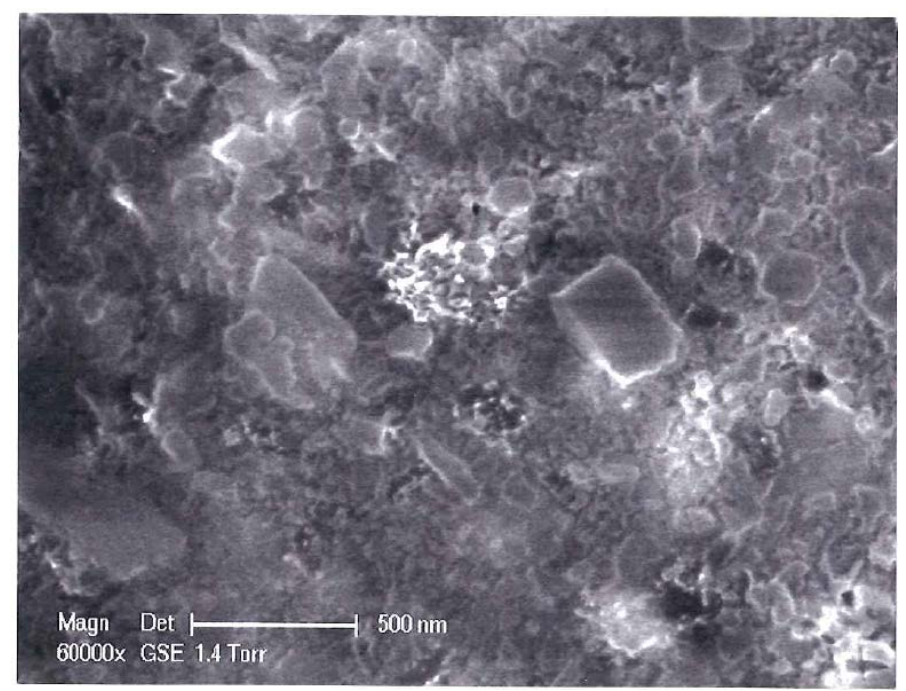

Figure 17. High resolution SEM photography $(60,000 \times)$ of a surface portion of the $p 7$ tectum. 


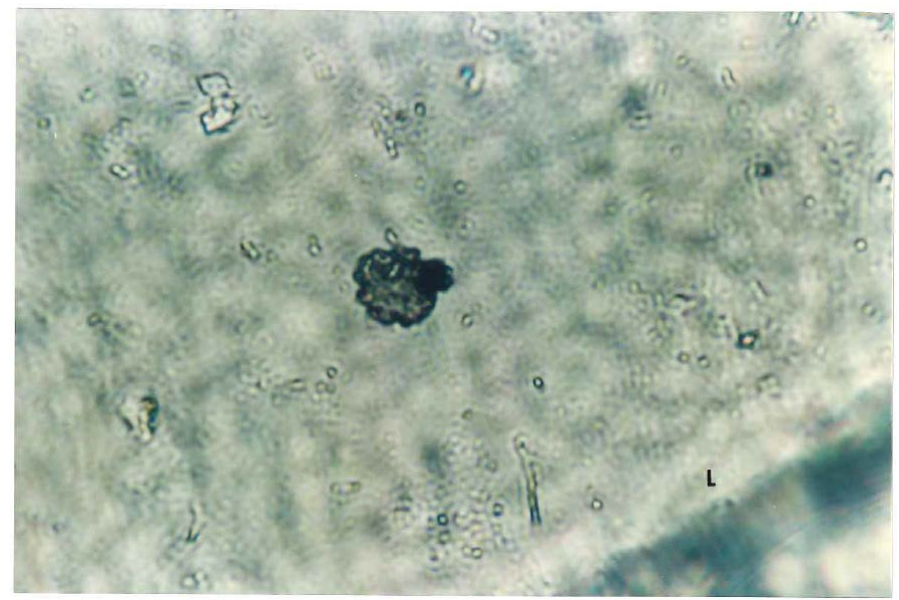

Figure 18. The p7 pollen $(1000 \times$ ) in optical microscopy (on some portion of the $\mathrm{R}$ area surface). L, the inferior border limit of the triangle.

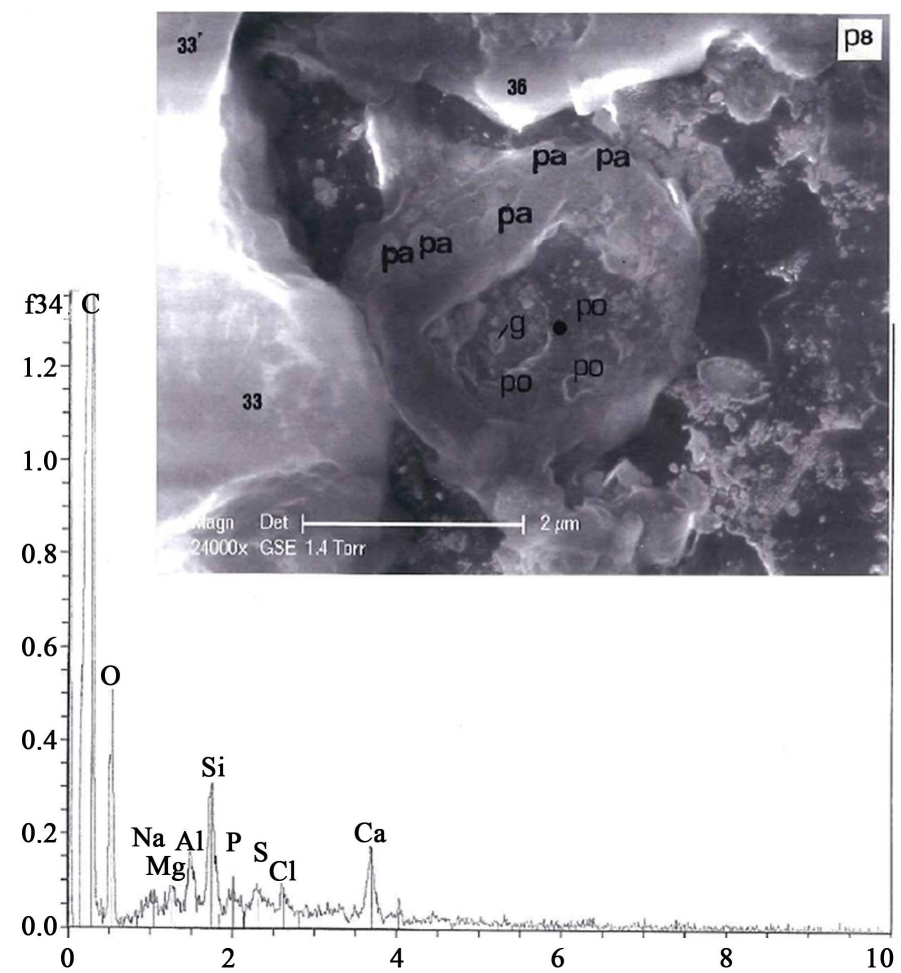

Figure 19. Above: SEM photography $(24,000 \times)$ of pollen p8; pa: papules; po: pores; g: granule; $\mathrm{f33}, 33^{\prime}$ and 36 are particles in the $\mathrm{F}$ area adjacent to $\mathrm{p} 8$. Below: spectrum of $\mathrm{p} 8$ at the black point indicated in the center of the pollen cavity. Adjacent particles f33-33' are some parts of a natron particle.

\section{Pollen p6 (d24-25)}

The photography of Figure 20 shows the $\mathrm{p} 9$ pollen. This prolate, but broken pollen, is seen in equatorial view. We can see on the photography the finely reticulate aspect of its surface.

Thickness at the costae colpi is about $16 \mu$. The break is located at the upper top of the pollen grain (and also at its right part), but we can distinguish the residual ends of the three colpis at the top breakage point. By projection out of the top of the upper break point and symmetrically in comparison with the equatorial costae, we can estimate that the pollen length is about $25 \mu$. 

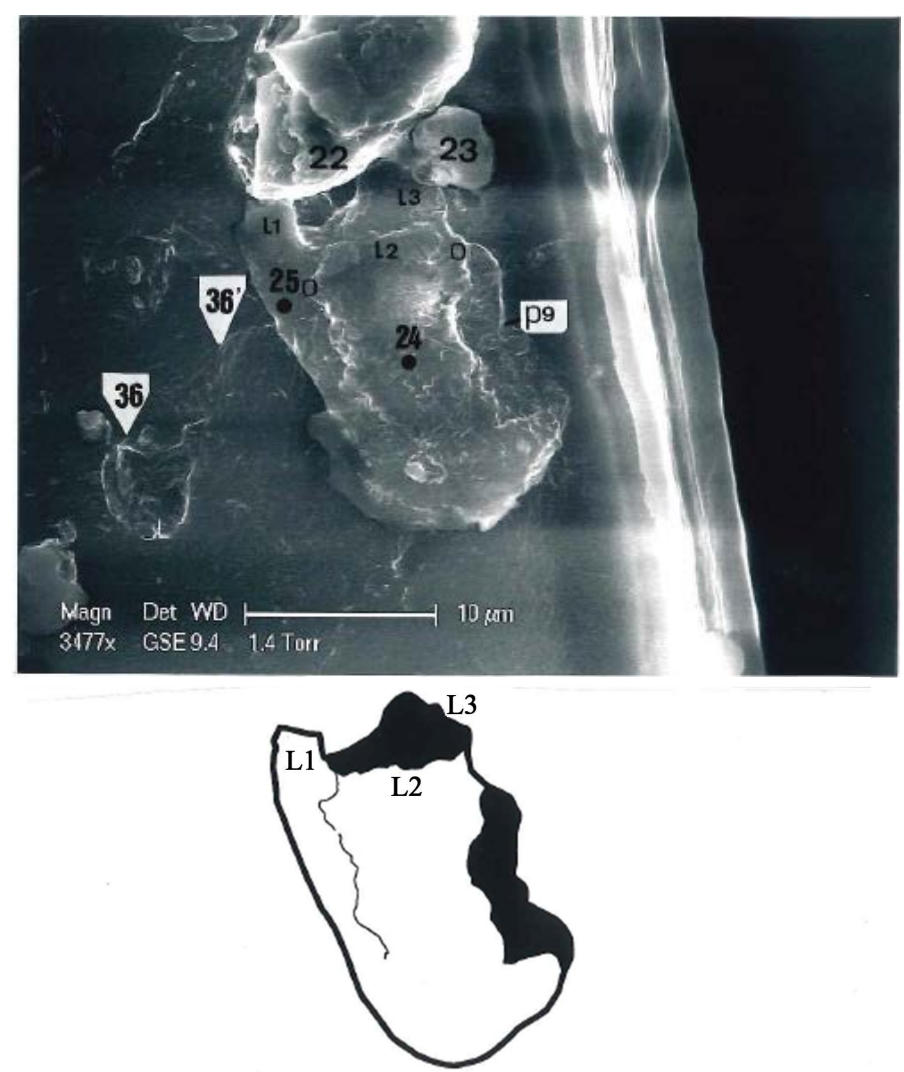

Figure 20. Above: SEM photography $(3477 \times)$ of pollen p9. L1, L2 and L3: the residual tops of the three lobes; o: extremities of the costae-colpi on L2; $\mathrm{d} 22$ and $\mathrm{d} 23$ are particles adjacent to the top of the pollen (probably d22, a thin micro-blade of silicate, had cutted the pollen at its top); $\mathrm{d} 36$ and $\mathrm{d} 36^{\prime}$ are two other particles adjacent to $\mathrm{p} 9$ in the $\mathrm{D}$ area; $\mathrm{d} 24$ and $\mathrm{d} 25$ are two parts (identical by elementary compositions) of the p9 pollen. Below: schematic representation of p9. L1, L2 and L3: the residual tops of the three lobes. Dark areas correspond to zones of breakage of the pollen.

The spectrum corresponding to elementary analysis of pollen p9 (Figure 21) establishes that it is mainly constituted of organic matter.

Pollen p9 characteristics correspond quasi-exactly to those of the Cercis siliquastrum pollen diagnosis (Horowitz \& Baum, 1967): prolate pollen $(26 \times 18 \mu)$; tricolporate grain; finely reticulate tectum; colpi lined by costae-colpi which are equatorially constricted.

So, pollen p9-although altered in structure because of breakage - is a pollen corresponding to the plant species Cercis siliquastrum (family Caesalpiniaceae), the "Judean tree" in vernacular terms.

Pollen p7 (a33)

The photography of Figure 22 shows the p10 pollen. It is an ellipsoid-circular pollen grain $8.7 \mathrm{x} 8.3 \mu$. Four lobes are visible on the photography. The four corresponding pores are more easily distinguished on the BSE photography of Figure 23. Elementary analysis of pollen p10 shows that it is mainly constituted of organic matter, but with an appreciable calcic component.

Pollen 10 -more perfect in form-is identical of pollens 6 and 7. These three pollens belong to the tree specie Ceratonia siliqua (family Caesalpiniaceae), the "carob tree" in vernacular terms. The three pollen grains are more or less calcified, and dried.

\section{Spores}

There are at least a total number of twenty-one spores on the surface of the triangle; twelve of them are identified. They are grouped in three main types: type 1 (Aspergillus), three spores (a12, a21 and b57); type 2 (Penicillium, eight spores (h44, j1, j35, k58, o5, p38, p55 and r31); type 3 (Cladosporium sphaerospermum), only one spore (j48). 


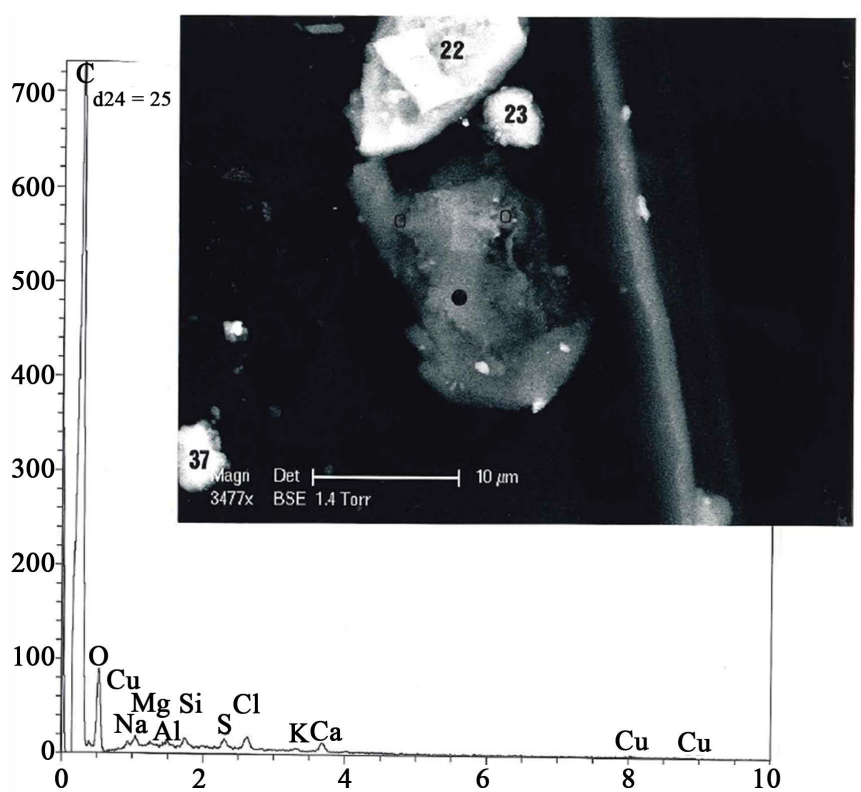

Figure 21. Above: SEM photography (3477×, in BSE) of pollen p9; 222,23 and 37 are particles adjacent to $\mathrm{p} 9$ in the $\mathrm{D}$ area; O: costae extremities. Below: elementary analysis of $\mathrm{p} 9$ at the black point indicated.
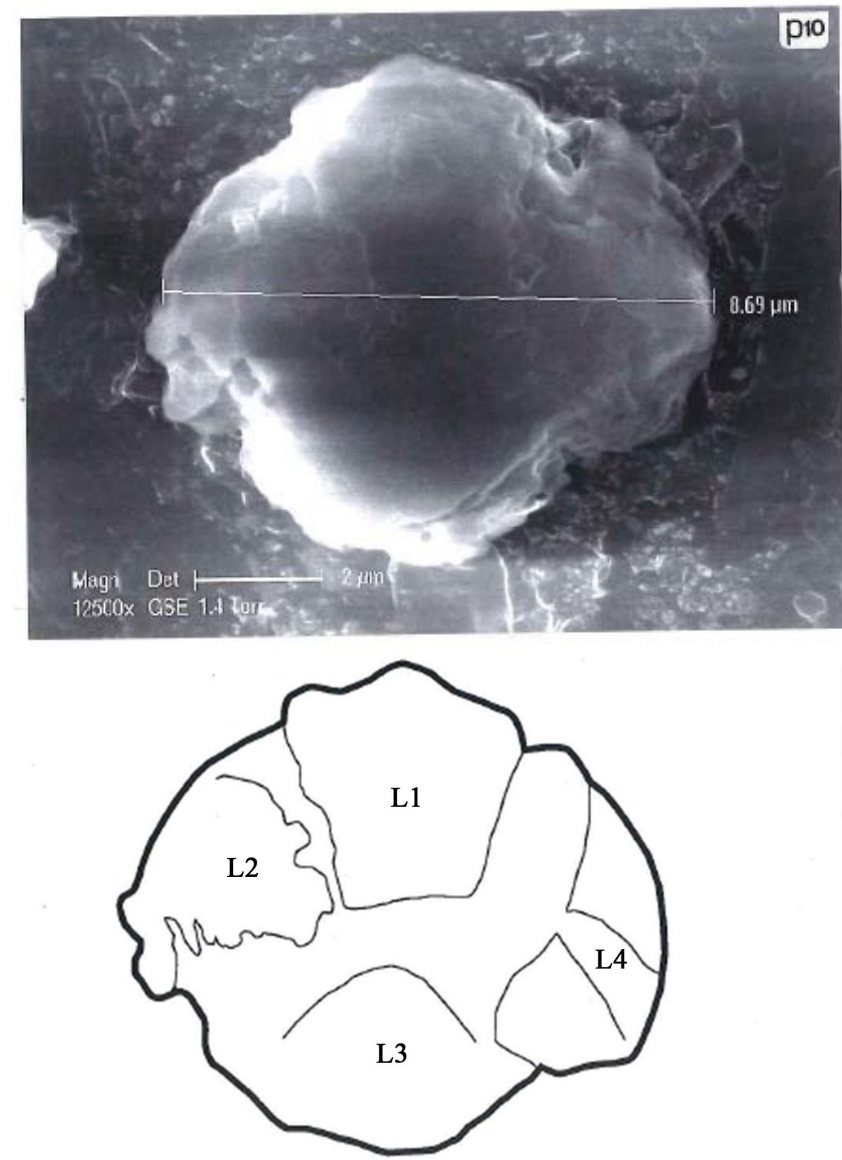

Figure 22. Above: SEM photography $(12,500 \times)$ of pollen p10. Below: schematic representation of $\mathrm{p} 10$, with its four lobes (L1, L2, L3 and L4). 


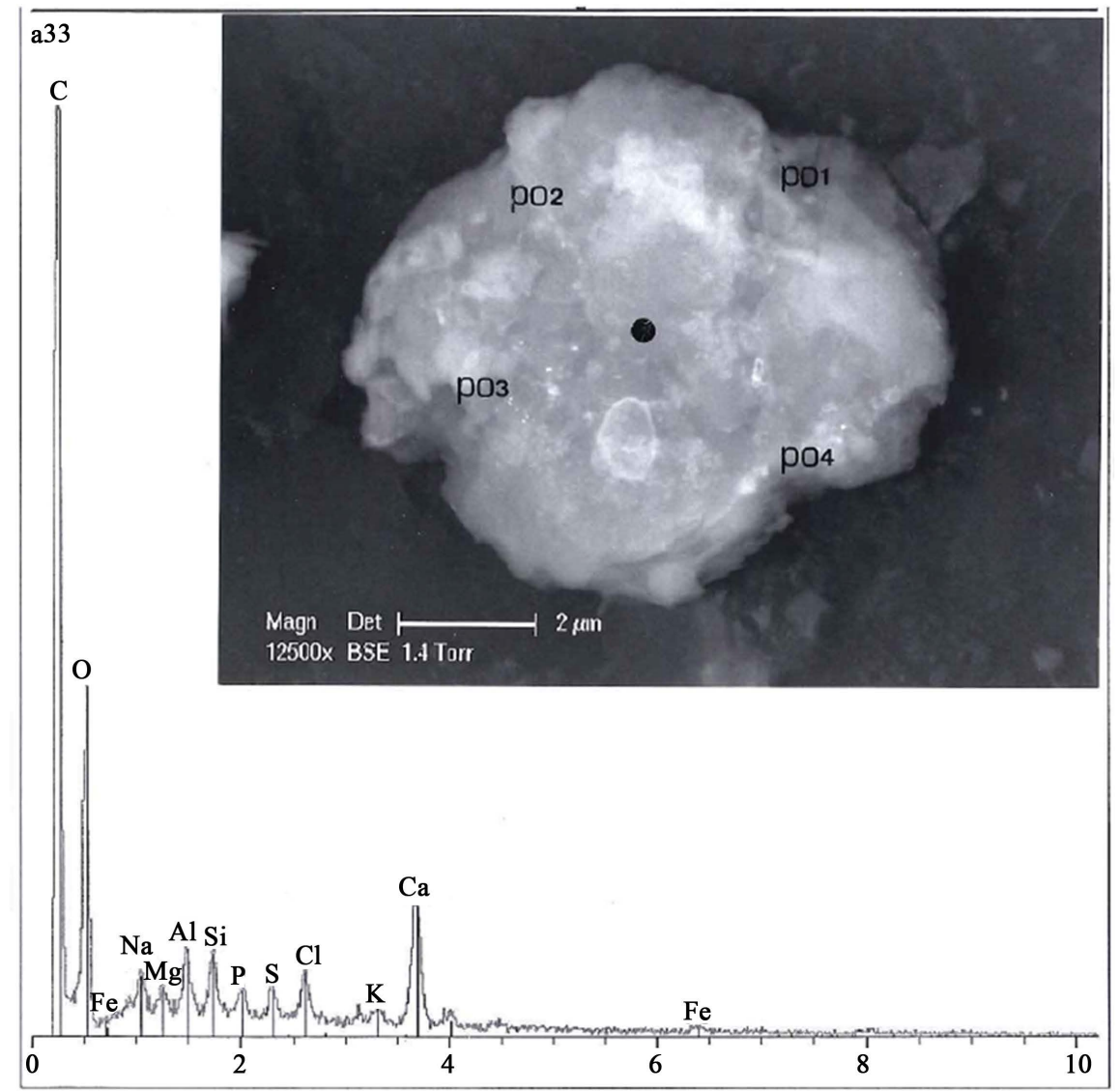

Figure 23. Above: SEM photography $(12,500 \times$, in BSE) of pollen p10. Locations and aspects of the four pores (p01, p02, p03 and p04) are shown. Below: elementary analysis of p10 at the black point indicated.

The three spores of type 1 are located on the top of the triangle, whereas type 2 spores are dispersed on its basis. The spores are not adjacent to each other. Spore j48, which morphology is very well kept, is located at the edge of the $\mathrm{J}$ area.

Spore j48 is the biggest in size (diameter about $5 \mu$ ); other spores have a diameter of about 2-3 $\mu$ only. Spore morphologies are more or less well kept, but it is not possible to distinguish those recent from those ancient.

Elementary analyses show that carbon and oxygen are the most important constituents of spores; some of them (b27, for example) are partially calcified, and some others (h44, for example) are salted. We have not observed any case of germinating spores.

While all spores observed are rounded, spore b2 is biacute in form (length $7 \mu$ ); its wall is thick, and very resistant to X-rays. It is, possibly, a spore of Gonaderma (Basidiomycete).

\section{Discussion}

We have found ten pollen grains on the surface of the triangle. Only one of them (p2) remained unidentified. We determined species for seven pollens: p1, p3, p4, p6, p7, p9 and p10. Three pollen grains (p6, p7 and p10) belong to Ceratonia siliqua; two (p3 and p4) belong to Myosotis ramosissima; $\mathrm{p} 1$ and $\mathrm{p} 9$ belong to Balanites aegyptiaca and Cercis siliquastrum, respectively. We determined one pollen (p5) at the gender level only (Galium) and another (p8) at the family level only (Chenopodiaceae). All these data are summarized in Table 2.

So we found ten pollen grains on the triangle surface, which corresponded to an area of $0.42 \mathrm{~mm}^{2}$; this gave an estimate (for the TS), of more than twenty pollens per $\mathrm{cm}^{2}$. Frei reported, orally, that he had found it-at least - in his material "only about one pollen grain per square centimetre of tape".

For such a low number $(=10)$ of pollens detected, we could not determine if there was a dominant specie in 
Table 2. Taxonomic determinations of the ten pollen grains.

\begin{tabular}{|c|c|c|c|c|c|c|}
\hline Pollen numbers & Pollen & Types & Genus & Species & Family & Present in the Near-East \\
\hline p1 & + & Tricolporate & Balanites & Aegyptiaca & Zygophyllaceae & + \\
\hline p2 & + & Prolate & $?$ & & & \\
\hline p3 & + & Rectangular & $\begin{array}{l}\text { Probably the same } \\
\text { as the following }\end{array}$ & & & - \\
\hline p4 & + & Rectangular & Myosotis & Ramosissima & Boraginaceae & - \\
\hline p5 & + & Colporate & Galium & $?$ & Rubiaceae & + \\
\hline p6 & + & Tetracolporate & Ceratonia & Siliqua & Caesalpiniaceae & + \\
\hline p7 & + & Tetracolporate & Ceratonia & Siliqua & Caesalpiniaceae & + \\
\hline p8 & + & Periporate & $?$ & & Chenopodiaceae & + \\
\hline p9 & + & Tricolporate & Cercis & Siliquastrum & Caesalpiniaceae & + \\
\hline p10 & + & Tetracolporate & Ceratonia & Siliqua & Caesalpiniaceae & + \\
\hline
\end{tabular}

this sample; but Ceratonia siliqua represented about $30 \%$ of this weak total.

A quasi-constant characteristic we observed about the pollen grains found was their important reduction in size (dry pollens) compared to their modern counterparts: the pollen volumes were reduced for about one half or more for pollen p1 (Balanites aegyptiaca), for pollen p5 (Galium) and for the three specimen pollens p6, p7 and p10 (Ceratonia siliqua). In the case of pollen p8 (Chenopodiacea), very small in size, water loss was also evident because of the cupped form pollen of this grain.

A rapid calcification process is responsible for the shape conservation of the two pollens $\mathrm{p} 3$ and $\mathrm{p} 4$ (Myosotis ramosissima). Probably some structural properties (crest architectures) of these rectangular grains are at the origin of their shape conservations; but it is mainly calcification that permits preservation of the fine ornamentation visible on the pollen $\mathrm{p} 4$ surface.

Calcification is constitutive for pollen grain $\mathrm{p} 5$, as we can observe it by the fine architecture and disposition of the calcite micro-grains on the crests and in the grooves. Pollens p6, p7 and p10 are notably calcified. Pollen p9 is not calcified at all.

Pollen morphology is relatively well kept in almost all cases, which permits precise determinations. It is because of the rigidity of its envelope that pollen p9 (Cercis siliquastrum), broken at its top, is kept in size, form and in details of its structure.

A remarkable observation about the three plants (Ceratonia siliqua, Balanites aegyptiaca and Cercis siliquastrum) whose pollens we find are their geographic distributions (Table 3), mainly in the Near-East, as not being an absolute proof, represents an indicative strong argumentation in favour of the Palestinian origin of the TS. None of these three sorts of pollen grains were listed in Frei (1982) or in Danin et al. (1999).

For these three trees or shrubs, pollen was not wind-borne but was carried by insects (Horowitz \& Baum (1967) reported their entomogamy mode of pollination). This establishes the local mode of pollen dissemination of these three plants.

The habitat of the palm tree of the desert (Balanites aegyptiaca) is oases. The carob tree (Ceratonia siliqua) is a dioïc tree (five to seven metres high). This originates from East-Mediterranean countries (Konate, 2007). It is a dominant specie characteristic of the maquis of sclerophyl trees; the carob tree is nowadays a cultivated tree, exploited for its pods.

Over $10 \%$ of the pollens mentioned by Frei (1982) and by Danin et al. (1999) correspond to plants flowering in the second half of the year. Ceratonia siliqua is a distinctly thermophilic specie; it is the only Mediterranean tree with a main flowering season in autumn (July to October), similar to many truly tropical plants.

The Judean tree (Cercis siliquastrum) is one of the most characteristic dominant trees in the lower zone ( 0 to 300 metres) of the Mediterranean evergreen maquis. It is a small tree, less than ten metres high. Extensive populations in the Yemen highlands led to the assumption that Arabia might have been the original home of the gender (Zohary, 1982). There was ample evidence that the Judean tree was an ornamental plant since the Antiquity; interestingly, it was ever recommended to plant this tree near orchards. 
Table 3. Habitats on geographical distributions of Ceratonia siliqua, Balanites aegyptiaca and Cercis siliquastrum (according to Horowitz \& Baum (1967)).

\begin{tabular}{cccc}
\hline Species & $\begin{array}{c}\text { Habitat in } \\
\text { Palestine }\end{array}$ & General distribution & Local distribution \\
$\begin{array}{c}\text { Ceratonia } \\
\text { siliqua }\end{array}$ & Maquis & $\begin{array}{c}\text { France, Corsica, Spain, Italy, Sicily, } \\
\text { Greece, Turkey, Cyprus, Syria, } \\
\text { Lebanon, Libya, Tunisia, Algeria }\end{array}$ & $\begin{array}{c}\text { Galilae, Carmel, Gilboa, Samaria, } \\
\text { Judean mountains and coastal plains, } \\
\text { Balanites } \\
\text { aegyptiaca }\end{array}$ \\
Oases & $\begin{array}{c}\text { Sahara, Libya, Egypt, Sudan, North-Nigeria, } \\
\text { Tchad, Ethiopia, Somaliland }\end{array}$ & $\begin{array}{c}\text { South of the Jordan valleys, } \\
\text { Aralley, deserts of Moab and Edom }\end{array}$ \\
& Maquis & $\begin{array}{c}\text { South of France, Italy, Sicily, } \\
\text { Balkan, reece, Turkey, Syria, } \\
\text { Lebanon,Iraq, Iran, Pontic }\end{array}$ & $\begin{array}{c}\text { Galilee, Carmel, Gilboa, } \\
\text { Samaria, Judean mountains }\end{array}$ \\
\hline
\end{tabular}

We present here some results showing that the pollen $\mathrm{p} 1$ (Balanites aegyptiaca) is contaminated by alumina-silicate sub-particles iron-rich, and that the pollen p7 (Ceratonia siliqua) is covered by sub-particles of gypsum; both the pollen grains are also contaminated by salt. These three minerals are commonly found in the particles of the soils of arid and desertic zones.

Galium is one of the largest genera of Rubiaceae, with some 400 species distributed in both temperate and tropical regions of the world (Mabberley, 1987); we cannot determine the species of the genus Galium (pollen p5) we have observed. The same is true for the pollen p8, the Chenopodiaceae family being represented by more than one hundred of genders largely distributed in the saline environments of subtropical and temperate zones of the world, especially around the Mediterranean, Caspian and Red Seas.

Myosotis ramosissimosa is a European specie. So, deposition of pollens $\mathrm{p} 3$ and $\mathrm{p} 4$ on the surface of the TS had very probably not been laid at the early times of its veneration in the Near-East. Because of the highly symbolic nature of this plant (forget-me-not) we can suppose reasonably that the corresponding flowers of myositis are deposited on the TS, as to do some form of reverence for this so venerable and highly symbolic object. We had ample evidence (Whanger \& Whanger, 1998) that this sort of veneration, with flowers and plants, was practiced in the early times of the TS story. In general, the burial in a tomb and the laying of flowers on the deceased bodies are symbolic actions of respecting and grieving for the departed.

Possibly, this form of early veneration had been practiced also with Cercis siliquastrum flowers, because one pollen grain of this specie was found on the Face of the TS. As for myositis flowers, flowers of the cultivated Judean tree that had been laid on the Shroud sometime during its story could be considered as some form of liturgical act.

\section{Acknowledgements}

We thank Dr Thierry Derouin, Director of the palynological Unit in the Phanerogamy Department of the Natural History Museum of Paris, for access to his reference pollen collections, for allowing us to use his photomicroscope, and for discussions and advice.

\section{References}

Danin, A. (2010). Botany of the Shroud: The Story of Floral Images on the Shroud of Turin. Jerusalem: Danin Publishing.

Danin, A., Whanger, U., Baruch, U., \& Whanger, M. (1999). Flora of the Shroud of Turin. St. Louis: Missoury Botanical Garden Press.

Farey, H. (2014). Research Articles (5) Problems with Pollen. https://www.shroud.com/pdfs/n79part8.pdf

Ferguson, I. K. (1980). The Pollen Morphology of Ceratonia. Kew Bulletin, 35, 273-277. http://dx.doi.org/10.2307/4114571

Frei, M. (1982). Nine Years of Palynologycal Studies on the Shroud. Shroud Spectrum International, 1, 3-7.

Hesse, M., Halbritter, H., Zetter, R., Weber, M., Bucher, R., Frosch-Radivo, A., \& Ulrich, S. (2009). Pollen Terminology: An Illustrated Handbook. Wien and New York: Springer.

Horowitz, A., \& Baum, B. (1967). The Arboreal Pollen Flora of Israel. Pollen et Spores, 9, 71-93.

Konate, I. (2007). Diversité phénotypique et moléculaire du Caroubier. Doctoral Thesis, Rabat: Rabat University. 
Lucotte, G. (2010). Vérités sur le Saint Suaire. Anet: Atelier Fol’ fer.

Lucotte, G. (2012). Optical and Chemical Characteristics of the Mineral Particles Found on the Face of the Turin Shroud. Scientific Research and Essays, 7, 2545-2553.

Mabberley, D. J. (1987). The Plant Book. Cambridge: Cambridge University Press.

Maloney, C. (1990). The Current Status of Pollen Research and Prospects for the Future. The ASSIST Newsletter, 2, 1-7.

Marion, A., \& Lucotte, G. (2006). Le linceul de Turin et la Tunique d'Argenteuil. Paris: Presses de la Renaissance.

Rossignol, M. (1969). Sedimentation palynologique récente dans la Mer Morte. Pollen et Spores, 11, 17-38.

Whanger, M. W., \& Whanger, A. D. (1998). The Shroud of Turin: An Adventure of Discovery. Franklin, TN: Providence House Publishers.

Zohary, M. (1982). Plants of the Bible. Cambridge: Cambridge University Press. 